\title{
A review of soft wearable robots that provide active assistance: Trends, common actuation methods, fabrication, and applications
}

\author{
Carly Thalman ${ }^{1}$ (D) and Panagiotis Artemiadis 2 * (D) \\ 'Ira A Fulton Schools or Engineering, Arizona State University, Tempe, Arizona, USA \\ ${ }^{2}$ Mechanical Engineering, University of Delaware, Newark, Delaware, USA \\ *Corresponding author: Email: partem@udel.edu
}

Received: 10 January 2020; Revised: 25 May 2020; Accepted: 05 July 2020

Key words: soft robotics; wearable; exoskeletons; wearable robotics

\begin{abstract}
This review meta-analysis combines and compares the findings of previously published works in the field of soft wearable robots (SWRs) that provide active methods of actuation for assistive and augmentative purposes. A thorough investigation of major contributions in the field of an SWR is made to analyze trends in the field focused on fluidic and cable-driven systems, prevalent and successful approaches, and identify the future direction of SWRs and active actuation strategies. Types of soft actuators used in wearables are outlined, as well as general practices for fabrication methods of soft actuators and considerations for human-robot interface designs of garment-like exosuits. An overview of well-known and emerging upper body (UB)- and lower body (LB)-assistive technologies is categorized by the specific joints and degree of freedom (DoF) assisted and which actuator methodology is provided. Different use cases for SWRs are addressed, as well as implementation strategies and design applications.
\end{abstract}

\section{Introduction}

A new and rapidly growing topic of research in wearable technologies is soft robotics. Over the past decade, assistive soft wearable robotic (SWR) devices have been advancing at an exponential rate, branching into numerous categories such as mobility-assistance achieving activities of daily living (ADLs), robot-facilitated therapy, and human augmentation, to name a few. In robotics, the term "soft" is typically used to describe materials that conform to existing surroundings and are compliant when exposed to external forces or interact with objects of unknown geometries. The use of materials that are inherently soft is conducive to the development of robotic systems that have demonstrated potential for safer, more comfortable, and lower cost alternatives when compared to rigid counterparts (Schiele and van der Helm 2009; Wehner et al. 2013). Research on soft robotics has proven that using such systems is effective for human-robot interaction, improved durability, and increased user comfort (Majidi 2013). It is a field with much promise and many novel technologies that are quickly beginning to change the way we think about wearable, assistive mechanisms (Majidi 2013; Bao et al. 2018).

The objective of this review is to analyze existing SWR devices in order to identify trends in the assistive robotics field and outline how a rapidly expanding topic has branched into different methodologies. This review presents a thorough look into how current research groups are aiming to assist the 
human body, collated by upper body (UB) and lower body (LB) categories. Trends of actuator methodologies used in the field are examined, and the benefits and drawbacks to each are identified for future investigation through a comprehensive analysis of recent work in this topic over the past decade.

\section{Trends in Soft Wearable Robotics}

\subsection{Soft robotics in wearable assistive technology}

Soft mechatronic technologies have become more reliable, effective, and well known over the last decade and have become an attractive solution for wearable robotic technologies (Bao et al. 2018). There has been a gradual advancement from rigid exoskeletons with isolated compliant methods of actuation toward a paradigm of entirely soft, garment-like wearables that feel nearly transparent to the user (Granberry et al. 2017). Wearable robotic devices made from soft, compliant materials have been gaining momentum in both academic and commercial settings over the past decade (Bao et al. 2018; Cianchetti et al. 2018). The lightweight, low-cost characteristics of garment-like devices forgo heavy, bulky, and rigid components in favor of inherently soft and compliant materials such as silicone elastomers, fabrics, and other forms of flexible materials (Coyle et al. 2018). The forgiving nature of the materials helps to alleviate issues with joint alignment that can be observed in some rigid exoskeletons (Schiele and van der Helm 2009) and provides safer interaction with people and the environment around the robotic system. The compliance of the materials can easily conform to its surroundings, the user's joints, or the objects with which it interacts (Galiana et al. 2012). Soft robotics offers an unmatched level of flexibility and versatility, resulting in systems that mold easily to their surroundings and the user for increased comfort, safety, and ease of use.

\subsection{Definitions, scope, and application}

Some SWRs are entirely soft, monolithic, garment-like wearable devices, made from soft actuators, fabric, and other compliant materials, while other applications include minimal or reduced amount of rigid components as mounting points for the soft actuators. Categories of wearable robots can be simplified into four main groups as defined by Wearable Robotics Association (2015) and Exoskeleton Report (ExR) (2020): (a) military, (b) industrial, (c) consumer, and (d) medical. Most wearable devices aim to either provide assistance or augmentation. In this review, assistance is defined as an SWR with a goal of restoring a more "natural" movement of biomechanical behavior (Awad et al. 2017b) and serves a role in accomplishing ADLs (Spector and Fleishman 1998). Augmentation is defined as an SWR that applies active external forces to a healthy user to increase the capability, strength, and/or endurance of the said user.

In this review, SWRs are analyzed and sorted into upper body (UB) wearables or LB wearables categories. This review evaluates multiple types of actuator designs and approaches that provide active assistance. While the following sections briefly highlight the prevalence of passive types of assistance, this review focuses only on looking at SWRs that utilize active actuator assistance and therefore will exclude thorough examination or discussion regarding SWRs that rely on passive assistance. This review analyzes the two most prevalent and rapidly expanding methods of providing active power, actuation, and assistance in SWRs: cable-driven systems and fluidic actuation. While there are many other types of soft actuators being developed (as discussed in "Other types of actuation for SWRs" section), this review aims to break down and analyze some of the most widely explored actuator designs, methods, and applications for an SWR for cable-driven and fluidic actuation. Fluidic actuators are organized into subcategories based on the materials used in fabrication: McKibben/pneumatic artificial muscles (PAMs), elastomers, and textiles/fabric-based actuators. Each aforementioned actuator design will be discussed in greater detail in "Actuation methods and materials for SWRs" section.

\subsection{Growing trends in assistive SWRs over the decade}

In order to determine how rapidly the interest in this sub-field of soft robotics has begun to grow, a metaanalysis of publications in this category is performed to analyze the rate of expansion. IEEE Xplore is used 

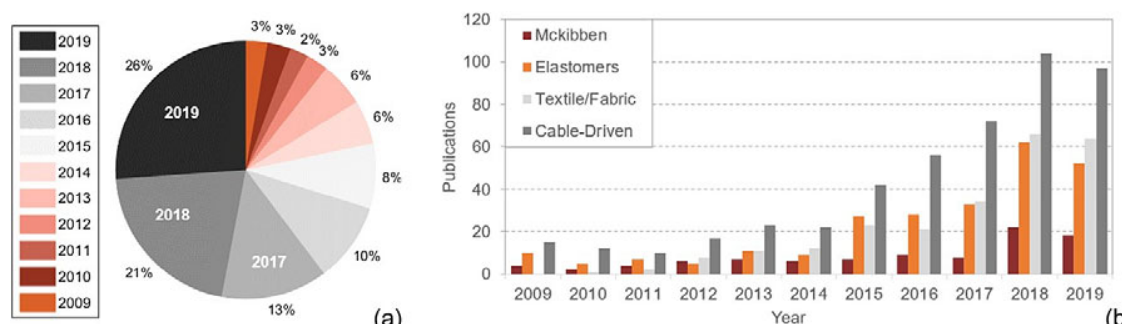

(a)

Figure 1. (a) Highlights the number of publications found on IEEE Xplore, including conference and journal publications, for research related to a soft wearable robot (SWR) between 2009 and 2019. Over the last decade, 57\% of the existing research in an SWR has been published in the span of the last 3 years. (b) Indicates the number of publications found on IEEE Xplore, including conference and journal publications, for research related to an SWR between 2009 and 2019. Papers are refined according to type of actuation.

as the primary search engine, and all meta-data are searched for the specified conditions to determine the number of publications that fit the selected criteria. For this search, only peer-reviewed articles published as part of IEEE conference proceeding and journals listed in the IEEE Xplore search engine were included for the final publication count. The search was limited by year for each search, and the total number of publications was recorded from years spanning from 2009 to 2019, to obtain a record of relevant publications across the last decade. These data were collected on January 9th of 2020. The search parameters were limited articles that included the terms "soft" and "robot" in the title or main text and also containing the words "wearable" and "assist" in the metadata of the publications. The resulting information of the meta-analysis is shown in Figure $1 \mathrm{a}$, which highlights that $60 \%$ of all publications on IEEE Xplore fitting the aforementioned criteria were published across 2019, 2018, and 2017, the last 3 years since this search was performed. These data indicate visible trends which show that soft robotics is itself a rapidly growing field, and additionally that research into an SWR has begun to expand at exponential rates in recent years. The last year evaluated (2019 from Figure 1a), shows the highest number of publications fitting within the confines of the refined search criteria, with $26 \%$ of the search results appearing in the most recent year.

To further evaluate the trends across SWRs published during this time, each search was refined in the respective year of publication by the actuation methods used (Figure 1b). These actuation methods, the pros and cons of each, as well as a more in-depth look, are included in the following sections. The increasing trend in publications and research interest can also be observed for each of the following actuation types, though it is notable that while cable-driven systems appear to remain predominant in most years, textiles and passive SWRs have begun to gain more popularity among published research. Where there were no notable SWR publications in 2009, this actuation method made up $16 \%$ of published work since 2017 and nearly 20\% of the published SWR research in 2019. A push for rapid advancement in wearable technologies in the early 2010 s may be partially attributed to military and government-funded projects in the field of robotics for more simplistic, lower cost, and lighter wearable devices to enhance human performance. Some of these major projects started with funding from DARPA and NASA grants with the Warrior Web (Asbeck et al. 2013) and the Armstrong (Kadivar et al. 2017). These exosuits aimed to reduce the overall metabolic cost to soldiers, who walk prolonged distances while carrying heavy loads, as well as reduce ergonomic issues and increase prevention of work-related injuries for astronauts.

\section{Actuation Methods and Materials for SWRs}

Fluidic actuators have been simplified and broken down into subcategories: McKibben/PAMs, elastomers, and textiles/fabric-based actuators. The pros and cons of each aforementioned actuator design will be discussed in greater detail in the following sections. 


\subsection{Development in fluid-driven soft actuators for SWRS}

One of the earlier soft actuator design and most commonly implemented method of actuation used in the soft robotics field is the fluid-driven approach (Yariott 1972; Petersen and Shepherd 2018). This method uses fluidic pressurization of specific cavities within the soft actuators to entice some kind of motion or generate force and can be traced back to initial designs from the 1970s and early 2000s (Yariott 1972; Noritsugu 2005). Pneumatically powered systems use compressible fluids to generate variable stiffness within specific actuators. Compressed air is most commonly used due to low viscosity, high compressibility, accessibility, and low cost (Ding et al. 2014). However, pneumatic systems have suffered from issues with latency and controllability when expected to interact or react to the user's kinematic or surrounding feedback (Malcolm et al. 2013; Ding et al. 2014). This review analyzes methods of soft actuation when applied to wearable devices, which are discussed in the following sections for McKibben/ PAMs, elastomers, and textiles/fabric-based actuators.

\subsubsection{Pneumatic artificial muscles/McKibben}

The PAM is one of the earliest developments in soft actuators for wearable devices, dating back as far as the 1970s for initial documentation (Figure 2a) (Yariott 1972; Klute et al. 1999). PAM actuators are typically characterized by a uniaxial contraction force upon actuator pressurization, which can be used to apply high tensile forces that closely resemble the mechanisms of human muscles contracting (Noritsugu 2005). When unactuated, PAMs have an intrinsic compliance from the soft materials that are nearly transparent to the user's natural kinematics in comparison to a rigid exoskeleton. The McKibben muscle (or braided PAM) is a well-known PAM actuator (Yariott 1972; Klute et al. 1999; Davis et al. 2003) that began introducing the concept of using soft materials to create a robotic actuator for human assistance in the early 2000s (Noritsugu 2005; Kobayashi et al. 2007). McKibben muscles consist of a cylindrical shell (often a type of braided mesh) that is capable of radial expansion and becomes inextensible at a maximum threshold (Klute et al. 1999; Sasaki et al. 2005b). The shell contains an airtight, thin-walled rubber tube



Figure 2. This figure provides a brief overview of different actuation methods used in soft exosuits: (a) Improved McKibben-type actuators braided into a mesh for higher contraction, lower profile, and a wider range of bending mechanics (Hiramitsu et al. 2019), (b) an elastomeric actuator that can be mechanically programmed to achieve different types of bending (Yap et al. 2015a),

(c) a stiffening beam textile actuator designed to resisted bending and buckling

(Miller-Jackson et al. 2019a), (d) new fabrication methodologies to create fabric-based inflatable actuators (Yang and Asbeck 2018), (e) shows fabric-based inflatables based on fiber reinforcement to induce different types of motions (Cappello et al. 2018a), and (f) a cable-driven soft wearable robot (SWR) device using Bowden cables to provide assistance (Awad et al. 2017b). 
with hyperelastic properties and is capped on both ends with an inlet for pressurization (Yariott 1972). Once pressurized, the tube expands the radius of the shell, inducing an overall contraction in the PAM actuator and an increasing tensile strength (Majidi 2013). McKibben muscles have a high force-to-weight ratio which makes them a popular choice when assisting human joints that require high torque (Teng et al. 2012; Wehner et al. 2013). McKibben muscles can have low bandwidth for certain human movements (Wehner et al. 2012) and can cause discomfort related to friction from the constantly varying surface area when in contact with the body (Davis et al. 2003).

Some PAM actuators address these issues by decreasing the overall size for more effective operation (Hiramitsu et al. 2019) and increasing the types of motions that the actuators can achieve (Sasaki et al. 2005a; Hassanin et al. 2017; Funabora 2018). These new approaches are opening doors to biologically inspired exosuits that have the high force-to-weight ratio of a McKibben muscle (Bilodeau et al. 2018) but with less weight, bulk, lower operating pressures, and a higher degree of transparency and flexibility for the user (Abe et al. 2018; Hiramitsu et al. 2019).

\subsubsection{Elastomeric fluidic actuators}

Wearable robotics began to embrace new types of soft actuators made from hyperelastic elastomers and other polymers shortly after the McKibben muscle began attracting researchers to using compliant actuators (Figure 2b) (Noritsugu et al. 2004; Noritsugu 2005). Elastomers and soft robotics were already the fields of research that were well in the process of becoming an emerging field, but it was not until the early 2010s that elastomeric actuators started maintaining a presence in the wearable robotics community (Petersen and Shepherd 2018). Initial investigations into using hyperelastic materials for actuator designs revealed functional implementation of using the actuators to assist the human hand (Noritsugu et al. 2004). Elastomeric actuators are forgiving when interacting with surroundings of a complex or unknown geometry (Galloway et al. 2013). The major advantage to systems of such high compliance is the simplistic, underactuated nature of the actuator, and successful examples in human assistance in the mid-2010s for rehabilitation have been showcased featuring silicone-based actuators (Oguntosin et al. 2015; Polygerinos et al.2015; Wilkening et al. 2015). Due to the generally lower force output from fluidic elastomer actuators, a wide majority of applications have focused on assisting the hand or wrist but some focused on the lower limbs (Park et al. 2014b).

PneuNet actuators became a popular design choice for many researchers in an SWR following the launch of the open-source instructional website "Soft Robotics Toolkit" (Holland et al. 2014) which was released by Harvard University in 2014. This design hosts several individual hollow units or chambers formed in a single plane, connected by a central cavity to allow pressurization of all chambers (Mosadegh et al. 2014; Yap et al. 2015b). Strain-limiting material is embedded in the base of the actuator. Upon pressurization, the chambers begin to expand, and due to the difference in strain at the top of the expanding chambers and the constrained layer along the base, the actuator begins to curl (Polygerinos et al. 2015) Recent advancements utilizing elastomeric actuators center around applications where low forces and high compliance are needed. Elastomeric actuators in more recent designs have integrated multimaterial properties into a single actuator during the fabrication process of casting and curing silicone molds to generate a wide variety of actuator designs (Polygerinos et al. 2017). Other materials have been used to generate a wide range of motions (RoMs) and actions for each actuator, such as contraction (Low et al. 2016; Wirekoh and Park 2017; Han et al. 2018), bending or curling (Li et al. 2020), and expansion (Zhang et al. 2019a) for rehabilitative purposes generally focused on the hand, wrist, or a weakened ankle.

\subsubsection{Fabric-based inflatables and textiles}

Many actuators used in SWR designs in recent years have switched to a fabric-based methodologies, using soft actuators made from fabrics and other forms of textiles and thin films to make soft exosuits more garment-like with reduced form factors (Figure 2c-e) (Granberry et al. 2017; Park et al. 2019b). Research has been conducted with fabric-based soft actuators since the early 2000s (Noritsugu et al. 2008; Yang 2017), even before the concept became widely popular to the SWR community. Thin-walled, airtight 
bladders made from binding two or more layers of the material together to form a pouch (Niiyama et al. 2015). Fabrics have been used to make soft actuators by using materials that bind together chemically with adhesive, thermally, or with ultrasound welding processes (Yap et al. 2017). The fabrics often do not possess the same hyperelastic properties as the silicone-based actuators, and so design considerations often revolve more heavily around geometric programming of materials (Khin et al. 2017). The benefits of using a single layer of thin film or textile is the simplicity in the final design, as well as the low profile the resulting actuator will possess when at atmospheric pressure. When depressurized, most textiles return to a state in which there is minimal volume or thickness in the actuator, which prevents the body of the actuator from becoming a hindrance to the movement of the user more so than rigid robotic counterparts (Chung et al. 2018). A combination of material properties, textiles, and basic geometric configurations of bladders is used to achieve the desired motion and force output (Felt et al. 2018; Cappello et al. 2018a).

New developments in fabric-based inflatable textiles have allowed for the implementation of new materials that can achieve a high variety of deformations and force translations (Cappello et al. 2018a; Realmuto and Sanger 2019). Fabric-based actuators have also been created to mimic the behavior of bellows to create a bending or rotary motion, similar in mechanical principles to the PneuNet actuator (Khin et al. 2017; Felt et al. 2018; Thalman et al. 2018; Yang and Asbeck 2018; Miller-Jackson et al. 2019b). Similar to fiber-reinforcing elastomers, design and characterization of fabric actuators can be performed by combining inextensible fabrics with extensible fabrics, such as spandex or neoprene to obtain the desired actuator behavior (Cappello et al. 2018a; Realmuto and Sanger 2019). Other common methods of fabrication include heat-welded thermoplastic polyurethane (TPU) (Niiyama et al. 2015) and fabric-based inflatables made from weather-proof nylon or women mesh (Yap et al. 2017; Abrar et al. 2019; Thalman et al. 2019). Some fabric-based designs and textiles are striving to create smart garments and have developed sheets of fabric controlled through pneumatics (Funabora 2018; Hiramitsu et al. 2019).

\subsection{Cable driven}

Designing new, lighter weight, lower profile wearable robots began to converge toward main-streamed popularity around the early 2010 s as the term "exosuit" became more well-known and defined (Figure 2f) (Asbeck et al. 2014). While PAM actuators had been effective in providing assistance, SWRs rapidly gained attention from researchers with the introduction of cable-driven mechanisms, which aimed to address several issues observed in early developments of fluidic SWRs (Galiana et al. 2012; Asbeck et al. 2013). Cable-driven actuation (Figure 2f) can easily mimic behaviors of the human musculoskeletal system to assist specific motions (Asbeck et al. 2014; In et al. 2015; Awad et al. 2017b; Zhang et al. 2019b). These systems have developed significantly in the past decade and are still one of the more prevalent actuation methods used. Extensive research has been done in controllability (Ding et al. 2018), anchor points for applied loads (Yandell et al. 2020), and design (Kwon et al. 2019) to create high performing exosuits.

The cables (or tendons) are affixed to a point on the exosuit (typically a strap or tab made from inextensible synthetic fabrics or lightweight plastics) which interfaces with the human body to allow for proper force transmission to the targeted joint (Asbeck et al. 2014; In et al. 2015; Awad et al. 2017a). The cable is routed along the body and fed to a motor which, when activated, winds the cables to apply a tensile force to the anchor point to mimic the musculoskeletal behaviors of specified joint or area (Awad et al. 2017b). Selecting an ideal anchor point is critical to ensuring the forces are translated to the body safely and effectively, as misalignments can cause the SWR to underperform (Galiana et al. 2012; Asbeck et al. 2014). Actuator power is transmitted to the direct point of contact (Yandell et al. 2017) by engaging the motors or pulley systems to provide varying levels of tension and movement on each cable. Sheathing is often used to help reduce friction of the cables moving across the skin and reduce overall friction (Nilsson et al. 2012). The interface that attaches the cable to the user must avoid slippage, allow for predictable torque generation when the cable is tensioned, and be comfortable to the wearer (In et al. 2015; Asbeck et al. 2015b). Cable-driven actuation can produce high torques at a bandwidth higher than that of other methods of soft robotic actuation used with SWRs. As a result, cable-driven systems are a popular 

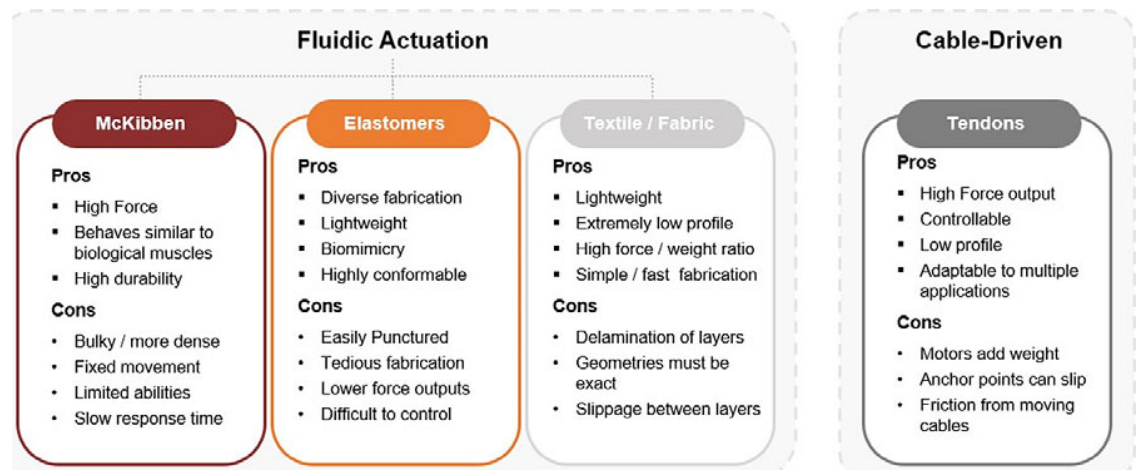

Figure 3. Brief overview of different actuation methods used in soft exosuits and the benefits/disadvantages of the listed types.

approach for augmentation of performance (Quinlivan et al. 2015). However, such high tensile forces applied at singular points on the body can cause discomfort (Schiele 2009; Quinlivan et al. 2015; Baltrusch et al. 2018).

\subsection{Comparison and critical evaluation of actuation methods in SWRS}

Each type of actuator has benefits and drawbacks depending on the application and the user. Designing an effective SWR means being able to select the materials and methods needed for the chosen application and ensure the selection will sufficiently meet the need. Listed in this section is a summarized overview of some of the pros and cons of each type of actuator. The highlights of each section are outlined in Figure 3 , which categorizes the actuation methods discussed in the previous sections.

\section{Pneumatic Artificial Muscles (McKibben):}

- Pros-McKibben muscles have a higher force/weight ratio and are able to withstand and generate higher forces during pressurization than other pneumatic designs. The actuators behave similarly to the human muscle, which simplifies design conceptualization and can easily provide assistance (Wehner et al. 2013). The lightweight and flexible nature of the inactive actuator make it easy to integrate onto a person without adding excessive weight to the users. The design of the braided mesh McKibben muscles is durable and can withstand the wear and tear of daily and repeated use.

- Cons-McKibben actuators face some issues with bulkiness and anchoring points (Kobayashi et al. 2007). Some McKibben muscles can be large in diameter to facilitate the needed force output, and the anchoring point of the point load from the actuator must be securely fixed on the user in order function as anticipated.

\section{Elastomeric Fluidic Actuators:}

- Pros-Elastomeric actuators can achieve high degrees of freedom with a single input and are forgiving against complicated joints or surfaces. Elastomers are less impacted by misalignment between the actuator and joint when subjected to an injection of pressurization and conform easily to their surroundings without additional input. Actuators are made from lightweight materials that have hyperelastic properties and expand and interact over larger surface areas against the body to avoid anchor point issues. This is useful for assistance to joints where additional bulkiness or anchor points may restrict user movement. These actuators can also reach a high degree of biomimicry which can be helpful when designing actuators to perform a specific biological or kinematic task.

- Cons-Elastomeric actuators begin to see a disadvantage in the aspect of controllability, due to the nonlinear behaviors exhibited upon pressurization and the general lack of sensing capabilities for 
position or control. Slower actuation time can be a limiting factor in the final application and higher force output can lead to inevitable structural failure, which would not be ideal for tasks that require higher force or cyclical repetition during assistance (i.e., heavy lifting or walking). Tethers to the pneumatic source may also be limiting to user motions or system portability.

Fabric-Based Inflatables and Textiles:

- Pros-Textile-based actuators have similar benefits to elastomeric alternatives; however, textiles are even lighter weight and can achieve a nearly undetectable profile when not pressurized (Yang and Asbeck 2018). Textile actuators can achieve higher force output at elevated pressure levels with inextensible fabrics, which increases the strength of the material properties to match the most durable inextensible layers. Textile or fabric actuators motion is predetermined by the materials and the corresponding material properties selected during fabrication (Cappello et al. 2018a). Fabrication techniques are easily accessible and simple, and design possibilities are limited mainly by the materials present or readily available for development (Yang and Asbeck 2018).

- Cons - Textile-based actuators face the same limitations as the aforementioned fluidic actuators with power source portability and latency. Other disadvantages can arise from mechanical fragility or failure, delamination of layers which create fluidic chambers, and slippage between layers of fabric and the human (Cappello et al. 2018a).

\section{Cable Driven:}

- Pros-The pros of cable-driven systems are low profile, lightweight, high torque, and increased controllability when compared to fluidic actuators. Highly complex motions can be achieved with a simple and underactuated input (Asbeck et al. 2013). This is beneficial for joints such as the hand or the shoulder or assisting multiple joints in series, such as LB limbs during walking. High torque is also easily achievable and controlled through fine-tuned input to the actuator motors, which allows for fast response time at precise and specified values. Cable-driven systems do not require a tether and are highly portable which is helpful to ADL tasks dealing with locomotion.

- Cons - Some drawbacks of cable-driven systems are friction, backlash hysteresis, nonlinearities (Dinh et al. 2017), and force translation to anchor points on the user (Galiana et al. 2012). Force and torque translation from the tendons to the joints relies on applying a point load to a soft or flexible interface (often garment-like exosuits or braces) which can result in slippage or hysteresis (Dinh et al. 2017). Slippage can often be observed between the skin and the fabrics, which can cause discomfort or inaccurate actuation based on nonobservable discrepancies with this displacement. The user typically must support the weight of the motors and other supporting hardware on their body (Asbeck et al. 2013).

\subsection{Other types of actuation for SWRs}

The following are actuation methods and designs that are beginning to be of more interest in the field of SWRs but have not yet become as effective or thoroughly investigated at this stage. These actuation methods have proven highly effective when implemented properly and are therefore worth noting. However, these actuator designs and methodologies are not within the scope of the review paper and will not be discussed in depth beyond this section.

Origami-inspired actuators are made from very thin, lightweight materials and designed to fold or bend in ways that mimic soft materials (Li et al. 2017; Sedal et al. 2018). Actuators can be controlled via small motors or are sometimes placed inside sealed thin film structures. Negative pressure can then be applied to remove the air from the thin film casing, forming a reinforced, folded structure encased inside the vacuum chamber contained in the thin film. Negative pressure can often be used just as effectively as positive pressure (Felt et al. 2018), which can be used in combination with other soft materials (i.e. foam, sand, paper, etc.) which occupy a certain volume at atmospheric pressure and compress and become stiff when subjected to negative pressure (Robertson and Paik 2017). Another form of actuation method used is the 
shape-memory alloy (SMA) actuator, which uses electrical current to affect the behavior, shape, and/or length of a material used in designing an actuator (Park and Park 2019). Another method is passive assistance from flexible or relatively soft materials. These actuators use materials with some intrinsic compliance or elasticity, to provide passive assistance to the user (Higuma et al. 2017; Lee et al. 2017b).

\section{Actuator Designs for SWRs}

Initial characterization of functional constraints for SWRs design requires initial identification of the actuation methods selected, which joint(s) will be assisted, and how the forces will be translated from the actuator to the user to provide effective, comfortable, and predictable assistance (Yandell et al. 2020). In most cases, the actuator is designed around a particular type of assistance that is needed at a selected joint on the human body or motion that is targeted for improvement. This can be done by utilizing actuators with different types of functionality (Connolly et al. 2015; Wang 2016). Throughout some of the most commonly seen SWRs, there are themes of the actuator designs designated for particular types of motion assistance and deformation methods. These were touched on briefly in "Cable driven" section but were more specific to elastomeric actuator design as an isolated concept. This section aims to highlight overarching themes of soft actuator designs commonly used in SWRs, specifically focused on fluidic actuators. These actuator designs have been categorized as shown in Figure 4 by (a) bellows/rotary, (b) extending/stiffening, (c) contracting/tensile, and (d) curling/bending designs.

\subsection{Bellows/rotary}

The first design in Figure 4a builds upon the PneuNet actuators described in "Cable driven" and "Comparison and critical evaluation of actuation methods in SWRs" sections, such as works presented at Harvard University (Polygerinos et al. 2015) and Arizona State University (Thalman et al. 2018), for elastomeric- and textile-based actuators, respectively. This design utilizes individual chambers or pockets that expand when inflated, as shown in Figure 4a. The base has a strain-limiting layer while the top is free to move. This allows for expansion across the top surface, while expansion is restricted at the base. Each chamber expands and exerts a contact force against adjacent chambers, which results in an effect that resembles bellows and generates a rotational motion (Miller-Jackson et al. 2019c). This actuator design is
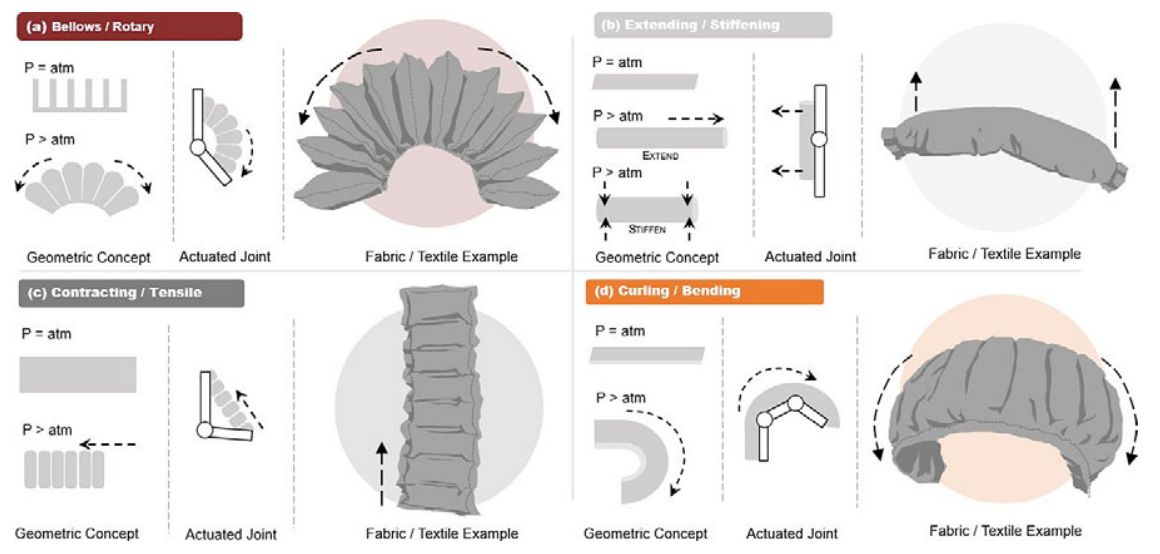

Figure 4. This figure provides an overview of the most commonly used actuator designs in soft wearable robots (SWRs) and the driving mechanical principles behind the motions supported by each listed category. Categories have been broken down into (a) bellows/rotary, (b) extending/stiffening,

(c) contracting/tensile, and (d) curling/bending designs. Each design is illustrated as a geometric representation of the actuator before and after injection of pressurized air, the actuator acting on a conceptual joint, and an illustration of a fluidic textile representation of these actuators for reference. 
effective for assisting joints in a single degree of freedom (DoF) and has been commonly used in flexion of joints (such as the elbow or a finger).

\subsection{Extending/stiffening}

The design forms a straight beam-like shape which will either stiffen or extend depending on the exact design and intended purpose (Figure $4 \mathrm{~b}$ ). Creating a beam of variable stiffness can allow for corrections in kinematics and support based on the torque and stiffness provided by the beam (Miller-Jackson et al. 2019a). This actuator design can provide variable stiffness as seen in the elastomeric design from National University of Singapore (Koh et al. 2017), where the inherent stiffness and recoiling effect of the beam are used to push the elbow into extension. Another example is the ExoBoot from Harvard University (Chung et al. 2018), which uses an inflatable textile beam to push the foot into plantarflexion. The beam design is beneficial when either placed laterally across a joint to serve as a split or pull into alignment when activated (Natividad and Yeow 2016) or is placed in acute angle of a joint to push the joint to straighten as the beam inflates and extends (Miller-Jackson et al. 2019c). This design is most commonly used in joint extension or joint bending prevention (e.g., finger or knee).

\subsection{Contracting/tensile}

This actuator design is the most common in exosuits, mainly because it includes cable-driven systems by nature, as well as McKibben muscles. Actuators that generate tensile forces mimic concentric contraction of human muscles, which provides many design concepts for SWRs that behave similarly to natural biological functions. Cable-driven actuation functions similarly to tendons in the body, and fluidic contracting actuators are designed to contract like muscles when an internal pressure is applied as depicted in Figure 4c. Researchers at Carnegie Mellon developed an elastomeric version of a PAM that generates a tensile force when pressurized (Wirekoh and Park 2017), and a fabric-based contracting actuator was developed from Arizona State University (Thalman et al. 2019). Contracting actuators are the most widely seen design and support joints in all motions from flexion to extension and are commonly seen assisting multiple joints in series (ankle + hip, fingers + hand, etc.).

\subsection{Curling/bending}

This design (depicted in Figure 4d) is in a separate category from the bellows/rotary design to distinguish the different methods in which this motion is achieved. Specifically, the materials used and the properties that interact when subjected to internal pressure or load will generate the resulting deformation. The top layer is made from a hyperelastic or highly extensible material, while the base layer is made from or constrained with an inextensible material. This difference in extensibility will cause the actuator to curl around the inextensible layer when pressurized (Noritsugu et al. 2008). The benefit of an actuator that can curl rather than rotate about a point is the forgiving nature, which can easily form around complex joints with a single input. This design is commonly placed on the outside of a joint, such as the finger to assist flexion. This is seen in the three discussed fluidic actuation methods with modified McKibben muscle from University of Salford (Hassanin et al. 2017), elastomeric design (Yap et al. 2015a), and fabric-based design from Harvard University (Cappello et al. 2018b).

\section{Fabrication Methods for Soft Fluidic Actuators}

The McKibben muscle (or braided PAM) is a durable soft actuator that is made from a single hollow tube, which is impermeable to air (Yariott 1972; Klute et al. 1999). This tube is inserted into a braided mesh tube of a slightly larger diameter. The braided mesh moves as able to slide and expand radially up until a certain point where it becomes inextensible. This braided mesh restricts the inner tube from overexpanding or weakening/bursting if overinflated. It also allows for the inner tube to inherit the material properties of the braided mesh when fully radially expanded which increases the strength of the actuator (Klute et al. 1999; 
Sasaki et al. 2005b). The ends of the layered tubes are capped with a metal ring or other airtight fitting that allows for a tube to connect. When pressurized, the tube expands inside the braided mesh, which experiences a radial expansion that results in a reduction in overall actuator length (Yariott 1972). This is the governing principle behind the McKibben muscle actuator, and it is a design that has managed to stay relevant through the past decade due to the versatility, low cost, and easy of fabrication (Noritsugu 2005).

Elastomers (or elastic polymers) typically have a low Young's modulus. A metric to measure the hardness of these materials is commonly identified using the Shore Hardness Scale, which can help determine how inertly stiff or flexible a material will be prior to actuator fabrication and during analytic and Finite Element Analysis (FEA) modeling (Holland et al. 2017). Elastomeric, fluidically actuated technologies have an extremely versatile RoMs, in categories of deformation types such as (a) bending, (b) expanding, (c) contracting, (d) elongating, and (e) twisting (Connolly et al. 2015; Wang 2016; Schmitt et al. 2018). These movements can be mechanically programmed into the actuator during the fabrication process (Galloway et al. 2013). Inextensible components are embedded within the elastomer to limit the strain at certain points and restrict expansion of the material during fluidic pressurization (Wirekoh and Park 2017; Heung et al. 2019). Fiber-reinforcement provides predictable, programmable motions depending on the orientation and positioning of the inextensible fibers (Galloway et al. 2013; Connolly et al. 2015). Strain-limiting layers such as a mesh or fabrics can be cured within the casting process to achieve a similar programmable motion (Polygerinos et al. 2015). For silicone-based elastomers specifically, there is a casting process that allows for complete customization and has been thoroughly explained and detailed for research groups and individuals to attempt independently (Holland et al. 2014).

Fabrics and textile-based actuator designs typically involve creating a specified, predetermined shape for a chamber and thermally or chemically bonding two or more layers of material together to form an airtight seal with a net shape of the desired chamber (Niiyama et al. 2015). Some actuators use only one type of material to achieve complete actuator fabrication (Yang and Asbeck 2018). They can be constructed from a heat-sealable material such as TPU, which forms an airtight seal when consistent pressure and heat are applied to form a thermal bond between layers (Niiyama et al. 2015; Thalman et al. 2018; Ang and Yeow 2019). Actuators may be formed from just TPU (or other heat-sealable thin films) layers (Niiyama et al. 2015), or they may use a fabric coated on one or both sides with a layer of heatsealable film (Yang and Asbeck 2018; Abrar et al. 2019; Thalman et al. 2019; Park et al. 2019b; MillerJackson et al. 2019c). As soft components are ideally lightweight and compact, actuators are designed to produce the highest forces possible with the smallest associated volumes (Coyle et al. 2018; Cappello et al. 2018a). New manufacturing methods optimize this process and reduce the time and level of complexity involved in fabrication (Miller-Jackson et al. 2019c). FEA studies have shown promise in providing realistic models for actuator design and optimization by simulating the behavior of soft materials (Holland et al. 2017; Coyle et al. 2018). This can allow for easier material selection and geometric optimization for mechanical programming of soft materials (Polygerinos et al. 2015). Automated methods of manufacturing are being developed utilizing custom three-dimensional (3D) printers for additive manufacturing using soft materials and Computer Numerical Control(CNC) methods of heat sealing textiles to increase complexity and accuracy of actuator designs while simplifying the laborintensive portions of actuator fabrication (Niiyama et al. 2015; Ang and Yeow 2019; Park et al. 2019b). Another method of creating these seams between layers is by using ultrasonic welding, which has successfully produced fabric-based actuators in previous work (Yap et al. 2017).

\subsection{Advanced fabrication methods used in SWR Actuators}

Some exosuits utilize smaller rigid or semi-rigid components as an integral part of the design, to create "anchor points," which relieve load on the wearer (Asbeck et al. 2013; Quinlivan et al. 2015; Li et al. 2018). By integrating anchor points correctly, strength and structure can be provided to the device without sacrificing flexibility and wearability for the user (Jiang et al. 2018). Rigid components are kept a safe distance away from the user, ensuring that the user only directly interacts with soft components 
(Balasubramanian et al. 2008). Rigid or semi-rigid components can also be embedded in the soft exosuit, used to help translate large forces more comfortably across the body and provide minor structural support within the exosuit (Quinlivan et al. 2015; Li et al. 2018).

Fabrication methods of soft exosuit devices are myriad and evolving at a comparable rate to the evolution of the designs themselves (Miller-Jackson et al. 2019c). New fabrication methods, and the developments that they facilitate, include the use of sew-free textiles (Yang and Asbeck 2018; Connolly et al. 2019), soft lithography for stretchable electronics, and the use of multimaterial 3D printers to integrate several different soft materials into the same part (Yap et al. 2016). In sew-free anisotropic textiles, a film is applied to the desired textile material to make it air impermeable (Connolly et al. 2019). Then, a water-soluble polymer is applied alongside a heat press to bond the seams in an air-impermeable way, and any excess polymer can be dissolved using water (Connolly et al. 2019). This eliminates the need for complex seamwork using traditional sewing techniques, allowing for faster turnaround and less technical skill required on the part of the manufacturer. It also allows for new materials that otherwise would not be feasible for soft robotics, like anisotropic textiles, to create actuators that exhibit anistropic properties (Connolly et al. 2019).

\section{Upper Body Soft Assistive Robotics}

UB assistance often focuses more on stationary rehabilitation, assistance in achieving the ADLs, or injury and fatigue prevention (Maciejasz et al. 2014). Figure 5 presents a brief look at some successful UB soft robots assisting various joints, and Tables 1 and 2 provide a more comprehensive list of some of the more recently developed technologies listed in this section. The UB has a high level of complexity and many DoF isolated to specific joints in concentrated areas that are easily affected by additional weight (such as the hand). The benefits of using SWRs for UB assistance avoid placing heavy components or restricting joint alignments on the user's arms or torso. Many of these SWRs for the UB are outlined in the following sections to discuss several types of assistance in more detail.

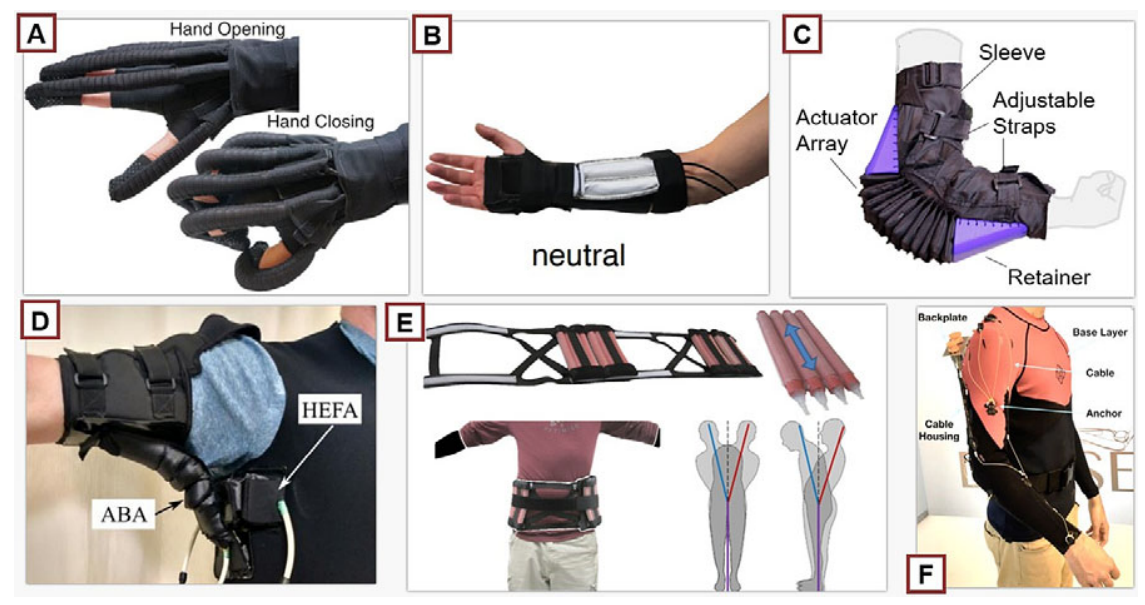

Figure 5. A brief survey of recent soft wearable robot (SWR) technologies for each of the following upper body joints: (a) A soft robotic hand developed at Harvard University at the Wyss Institute for Biologically Inspired Engineering (Cappello et al. 2018b), (b) a soft assistive device for the wrist made from fabric materials (Realmuto and Sanger 2019), (c) a soft elbow exosuit designed at Arizona State University (Thalman et al. 2018), (d) shoulder-assistive device also from Harvard University at the Wyss Institute for Biologically Inspired Engineering (O'Neill et al. 2017), (e) trunk orthosis from the Reconfigurable Robotics Lab at Ecole Polytechnique Fédérale de Lausanne (Robertson and Paik 2016), and (f) an upper body device that assists multiple joints via cable-driven actuation (Lessard 2018). 
Table 1. This chart illustrates the correlation between existing soft wearable robots (SWRs) for the upper body, showing the most prevalent method of actuation used related to the specific type of assistance provided at each joint of the upper body and the respective degrees of freedom that are assisted.

\begin{tabular}{|c|c|c|c|c|c|c|c|}
\hline Joint & Year & Soft wearable robot & Actuation & Method & Design & DoF & Motion \\
\hline \multirow[t]{13}{*}{ a. Shoulder } & 2008 & $\begin{array}{l}\text { Balasubramanian } \\
\text { et al. (2008) }\end{array}$ & Pneumatic & McKibben & Contraction & 2 & $\mathrm{Ab}, \mathrm{C}$ \\
\hline & 2019 & Abe et al. (2019) & Pneumatic & McKibben & Contraction & 1 & $\mathrm{~F}$ \\
\hline & 2012 & Galiana et al. (2012) & $\begin{array}{l}\text { Cable- } \\
\text { driven }\end{array}$ & $\begin{array}{l}\text { Bowden } \\
\text { cables }\end{array}$ & Tensile & 1 & $\mathrm{Ab} / \mathrm{Ad}$ \\
\hline & 2014 & Koo et al. (2014) & Pneumatic & Textile/fabric & Rotary & 1 & $\mathrm{Ab}$ \\
\hline & - & - & $\begin{array}{l}\text { Cable- } \\
\text { driven }\end{array}$ & $\begin{array}{l}\text { Bowden } \\
\text { cables }\end{array}$ & Tensile & 1 & $\mathrm{~F} / \mathrm{E}$ \\
\hline & 2016 & $\begin{array}{l}\text { Natividad and Yeow } \\
\quad(2016)\end{array}$ & Pneumatic & Textile/fabric & $\begin{array}{l}\text { Stiffening } \\
\text { beam }\end{array}$ & 1 & $\mathrm{Ab}$ \\
\hline & 2017 & Kobayashi et al. (2007) & Pneumatic & McKibben & Contraction & 3 & $\underset{\mathrm{C}}{\mathrm{F} / \mathrm{E}, \mathrm{Ab} / \mathrm{Ad},}$ \\
\hline & 2017 & O'Neill et al. (2017) & Pneumatic & Textile/fabric & Rotary & 2 & $\mathrm{Ab} / \mathrm{Ad}$ \\
\hline & - & - & Pneumatic & Textile/fabric & $\begin{array}{c}\text { Stiffening } \\
\text { beam }\end{array}$ & 2 & $\mathrm{~F} / \mathrm{E}$ \\
\hline & 2017 & Lessard et al. (2017) & $\begin{array}{l}\text { Cable- } \\
\text { driven }\end{array}$ & $\begin{array}{r}\text { Bowden } \\
\text { cables }\end{array}$ & Tensile & 2 & $\mathrm{~F} / \mathrm{E}, \mathrm{Ab} / \mathrm{Ad}$ \\
\hline & 2018 & Abe et al. (2018) & Pneumatic & McKibben & Contraction & 2 & $\mathrm{~F} / \mathrm{E}, \mathrm{Ab} / \mathrm{Ad}$ \\
\hline & 2018 & Han et al. (2018) & Pneumatic & Elastomeric & Extension & 2 & $\mathrm{~F}, \mathrm{Ab}$ \\
\hline & 2018 & Lessard (2018) & $\begin{array}{l}\text { Cable- } \\
\text { driven }\end{array}$ & $\begin{array}{l}\text { Bowden } \\
\text { cables }\end{array}$ & Tensile & 2 & $\mathrm{~F} / \mathrm{E}, \mathrm{Ab} / \mathrm{Ad}$ \\
\hline \multirow{7}{*}{ b. Trunk } & 2015 & Ohno et al. (2015) & Pneumatic & McKibben & Contraction & 1 & $\mathrm{E}$ \\
\hline & 2016 & Inose et al. (2016) & Pneumatic & McKibben & Extension & 1 & $\mathrm{E}$ \\
\hline & - & - & - & Textile/fabric & Stiffening & 1 & $\mathrm{E}$ \\
\hline & 2016 & Robertson and Paik (2016) & Pneumatic & Elastomeric & Bending & 2 & $\mathrm{~F} / \mathrm{E}, \mathrm{LF}$ \\
\hline & 2017 & Cho et al. (2017) & Pneumatic & McKibben & Extension & 1 & $\mathrm{E}$ \\
\hline & - & - & - & Textile/fabric & Stiffening & 1 & $\mathrm{E}$ \\
\hline & 2019 & Yang et al. (2019) & $\begin{array}{l}\text { Cable- } \\
\text { driven }\end{array}$ & $\begin{array}{l}\text { Bowden } \\
\text { cables }\end{array}$ & Tensile & 1 & $\mathrm{~F}$ \\
\hline \multirow[t]{21}{*}{ c. Elbow } & 2005 & Noritsugu (2005) & Pneumatic & McKibben & Contraction & 1 & $\mathrm{~F}$ \\
\hline & - & - & - & McKibben & Bending & 1 & $\mathrm{E}$ \\
\hline & 2005 & Aragane et al. (2008) & Pneumatic & Textile/fabric & Bending & 1 & $\mathrm{~F} / \mathrm{E}$ \\
\hline & 2014 & Koo et al. (2014) & $\begin{array}{l}\text { Cable- } \\
\text { driven }\end{array}$ & $\begin{array}{l}\text { Bowden } \\
\text { cables }\end{array}$ & Tensile & 1 & $\mathrm{~F}$ \\
\hline & 2015 & Nycz et al. (2015) & $\begin{array}{l}\text { Cable- } \\
\text { driven }\end{array}$ & $\begin{array}{r}\text { Bowden } \\
\text { cables }\end{array}$ & Tensile & 1 & $\mathrm{~F} / \mathrm{E}$ \\
\hline & 2015 & Wilkening et al. (2015) & Pneumatic & Elastomeric & Rotary & 1 & $\mathrm{~F} / \mathrm{E}$ \\
\hline & 2017 & Xiloyannis et al. (2017) & $\begin{array}{l}\text { Cable- } \\
\text { driven }\end{array}$ & $\begin{array}{r}\text { Bowden } \\
\text { cables }\end{array}$ & Tensile & 1 & $\mathrm{~F} / \mathrm{E}$ \\
\hline & 2017 & Koh et al. (2017) & Pneumatic & Elastomeric & Bending & 1 & $\mathrm{~F}$ \\
\hline & - & - & - & Textile/fabric & $\begin{array}{c}\text { Stiffening } \\
\text { beam }\end{array}$ & 1 & $\mathrm{E}$ \\
\hline & 2018 & Tripanpitak et al. (2018) & Pneumatic & McKibben & Contraction & 1 & $\mathrm{~F}$ \\
\hline & 2018 & Gao et al. (2018) & Pneumatic & Elastomeric & Bending & 1 & $\mathrm{~F}$ \\
\hline & 2018 & Thalman et al. (2018) & Pneumatic & Textile/fabric & Rotary & 1 & $\mathrm{~F}$ \\
\hline & 2018 & Chiaradia et al. (2018) & $\begin{array}{l}\text { Cable- } \\
\text { driven }\end{array}$ & $\begin{array}{r}\text { Bowden } \\
\text { cables }\end{array}$ & Tensile & 1 & $\mathrm{~F} / \mathrm{E}$ \\
\hline & 2018 & Li et al. (2018) & $\begin{array}{l}\text { Cable- } \\
\text { driven }\end{array}$ & $\begin{array}{r}\text { Bowden } \\
\text { cables }\end{array}$ & Tensile & 1 & $\mathrm{~F} / \mathrm{E}$ \\
\hline & 2018 & Lessard (2018) & $\begin{array}{l}\text { Cable- } \\
\text { driven }\end{array}$ & $\begin{array}{r}\text { Bowden } \\
\text { cables }\end{array}$ & Tensile & 1 & $\mathrm{~F} / \mathrm{E}$ \\
\hline & 2019 & Irshaidat et al. (2019) & Pneumatic & McKibben & Contraction & 1 & $\mathrm{~F}$ \\
\hline & 2019 & Abrar et al. (2019) & Pneumatic & Textile/fabric & $\begin{array}{l}\text { Extending } \\
\text { beam }\end{array}$ & 1 & $\mathrm{E}$ \\
\hline & - & - & $\begin{array}{l}\text { Cable- } \\
\text { driven }\end{array}$ & Tendons & Contraction & 1 & $\mathrm{~F}$ \\
\hline & 2019 & $\begin{array}{l}\text { Miller-Jackson et al. } \\
\quad(2019 \mathrm{c})\end{array}$ & Pneumatic & Textile/fabric & Rotary & 1 & $\mathrm{~F}$ \\
\hline & - & - & - & Textile/fabric & $\begin{array}{c}\text { Stiffening } \\
\text { beam }\end{array}$ & 1 & $\mathrm{E}$ \\
\hline & 2019 & Abe et al. (2019) & Pneumatic & McKibben & Contraction & 1 & $\mathrm{~F}$ \\
\hline
\end{tabular}




\subsection{Head and neck}

There are limited studies of soft robotics application above the shoulders. However, there are studies on how soft robotics can help with basic facial motor functions. So far this area of research is minimal, though could pose promise for future studies due to the biomimicry often seen in many SWRs. Due to limited or sufficient data on this particular joint, it is omitted from the final list of considered (real) options.

\subsection{Shoulder}

The shoulder joint is comprised of a combination of DoF and motions that become coupled during certain movements and remain separate entirely for other motions, which create a particularly complex location to provide assistance with wearable devices. The shoulder maintains several rotational DoFs that intersect and do not have perfectly perpendicular axes, as well as another DoF that moves as a translation of the center of the joint itself. This level of complexity has made the shoulder a difficult joint to assist with rigid robots, and many early designs required the user to be seated with their torso fixed in order to utilize the device (Table 1a).

Initial research into SWRs for the shoulder can be observed in the turn of the century, when McKibben actuators were the more common approach (Kobayashi et al. 2007; Balasubramanian et al. 2008). Initial designs were lighter than rigid counterparts and less complex, however, because McKibben muscles could only apply tensile forces the DoF assisted were limited. Significant issues with slippage were observed, and the translation of forces to the human body was not always comfortable for the user (Kobayashi et al. 2007). As cable-driven systems became more common in the 2010s, shoulder assistance with SWRs shifted away from McKibben and fluidic actuators and focused more on using tendons to manipulate the joint (Kesner et al. 2011; Galiana et al. 2012). These systems were far less bulky and conformed more easily to the joint, with less limitation on tensile force or contraction ratio which could support the full RoM, and also facilitate placement to allow support in more DoF (Kobayashi et al. 2007; Galiana et al. 2012). Development for shoulder SWRs became a more active research topic in the later 2010s as NASA began to invest in the "Armstrong," a wearable suit for astronauts that used tendons to assist the shoulder (Kadivar et al. 2017). It was around the time of this development that increasingly advanced textile actuators emerged in the field (Natividad and Yeow 2016; O'Neill et al. 2017) and McKibben muscles showed more sophisticated and effective designs (Abe et al. 2018). The shoulder has proven to be a difficult joint to assist, and some of the most prevalent SWRs tackling this goal are still seeking to find actuators that most closely resemble human muscle functions and placements (Abe et al. 2019).

\subsection{Back and trunk}

These SWRs are commonly seen to help prevent injuries before they occur when dealing with the back or trunk of the user (Table 1b) and usually focus on posture and lifting assistance (Babic ${ }^{\sim}$ et al. 2017). This is especially critical for factory or industrial workers, or other individuals who do repetitive heavy lifting (Babic ${ }^{\sim}$ et al. 2017; Lamers et al. 2018). Several soft systems utilize passive methods of actuation such as pretensioned elastic bands or pulley systems that help support the back at opportune moments for injury (Cho et al. 2017; Yang et al. 2019). The benefit of actuation that uses tension in-line with the spine is the ability to store and release energy during lifting with the flexion and extension of the trunk. Since the human trunk can be heavy, actuation methods to actively assist movement can be difficult when locating anchor points that do not impede motion or translate forces to become burdensome to other joints.

\subsection{Elbow}

SWRs for elbow assistance range from a focus in rehabilitation to injury prevention (Table 1c). These systems began in a consistent and similar methodology as wearable robots for the shoulder. The initial introduction of the McKibben muscle led to development emerging to design systems in robotics that would facilitate elbow rehabilitation without restricting movement of the user (Noritsugu et al. 2008). McKibben muscles quickly became an issue when translating tensile force to torque at the elbow joint, and with cable- 
driven systems gaining popularity in LB SWRs, designing cable-driven systems for the UB became a focus for SWRs (Koo et al. 2014). With only a single DoF to maneuver at the elbow, it became more common to integrate designs for assisting both joints simultaneously with underactuation (Abe et al. 2018). Cabledriven systems provide assistance that mimics the biological function of the muscles in the upper arm to enact flexion and extension (Xiloyannis et al. 2017; Chiaradia et al. 2018). By attaching cables to the base of the forearm and routing to an anchor point at the shoulder, the cables can be controlled to provide flexion and extension assistance at the elbow joint (Xiloyannis et al. 2017; Li et al. 2018).

Fluidic actuation approaches specific to the elbow begun to emerge in the 2010s with other pneumatic SWRs and varied stylistically to match the specific need the exosuit is trying to fulfill (Abe et al. 2018). Some used a bellows-type design to push the elbow into extension and pull it into flexion from the armpit area (Oguntosin et al. 2015), while others designed for rotary actuators placed on the exterior side of the elbow joint to apply a rotational torque to induce flexion assistance (Aragane et al. 2008; Noritsugu et al. 2008; Thalman et al. 2018). Elbow assistance is still a topic of high interest. It is less commonly seen as an isolated SWR for the particular joint. The elbow is commonly designed to be assisted as a part of a larger UB system as factors such as posture and weight/load distribution become more critical.

\subsection{Wrist and hand}

SWRs are effective for the human hand due to their ability to easily follow complex motion and utilize the compliance for an underactuated mechanism (Sasaki et al. 2005b). Table 2d-f lists several successful executions of SWRs for assistance to the hand and wrist. Underactuated SWRs use limited inputs for each segment of the hand and allow for reduced computing power and simplified control (Yap et al. 2015b). The goal for these technologies is to restore basic hand movement and functionality to regain independence and achieve ADL (Connelly et al. 2010). There has been a variety of adaptations of soft hand exosuits for rehabilitation over the past decade, and the hand in particular is an assistance location that has drawn a significant amount of attention from the SWR community. Some notable applications of soft robotics on the hand and wrist can be seen as far back as the early 2000s, utilizing the principles of McKibben muscles to modify the existing mechanical behavior to generate new and more helpful actuator performance (Noritsugu et al. 2004; Sasaki et al. 2005b).

Despite major shift of McKibben actuators and expanding capabilities, other avenues of soft actuation were being explored to provide assistance to the human hand. As cable-driven SWRs gained popularity, this strategy actuation is effective as it mimics the natural mechanics of the hand and tendons and often have a low profile, though often requires motors being placed somewhere on the arm or wrist. PAMs (Sasaki et al. 2005b), fluidic elastomers (Polygerinos et al. 2015; Zhao et al. 2016; Jiang et al. 2018; Shiota et al. 2019), and fabric-based inflatable (Noritsugu et al. 2008; Zhu et al. 2017; Realmuto and Sanger 2019) actuation methods have been used to achieve various levels of assistance and are typically all actuated using pneumatics, which pose similar uses of needed tubing and a pneumatic source. Fabric-based pneumatics have shown promise to avoid some of the issues of bulkiness observed in PAMs and elastomers. There is newly emerging research on soft exosuits for the wrist joint with focus on preventative assistance, as well as supporting forearm pronation and supination (Realmuto and Sanger 2019; Park et al. 2019b).

\section{LB Soft Assistive Robotics}

LB-assistive devices are commonly designed with the purpose of assisting or augmenting the human gait. Assistance is typically aimed at restoring a natural gait pattern to an impaired individual with abnormal gait adaptations. Augmentation is aimed at either increasing walking capabilities for a faster pace or reducing the metabolic cost for walking/running. Using SWRs for LB limbs is a major advancement that allows the user to interface with an LB robot without adding additional weight to their legs (Siviy et al. 2017). Adding weight to the limbs during walking increases the inertia of the limb while in motion which can cause unnatural gait adaptations and safety concerns with balance for increased risk of trips and falls (Browning et al. 2007). In the following sections, each joint will be discussed separately, even if particular devices span across assistance for 
Table 2. Continuation of Table 1, showing soft wearable robots (SWRs) for the upper body, specifically focused on the hand and wrist as this is an area that has been thoroughly explored by the listed groups using the actuation types specified in the following table.

\begin{tabular}{|c|c|c|c|c|c|c|c|}
\hline Joint & Year & Soft wearable robot & Actuation & Method & Design & DoF & Motion \\
\hline \multirow[t]{12}{*}{ d. Wrist } & 2005 & Noritsugu (2005) & Pneumatic & McKibben & Bending & 1 & $\mathrm{Ab} / \mathrm{Ad}$ \\
\hline & 2005 & Sasaki et al. (2005a) & Pneumatic & McKibben & Contraction & 2 & $\mathrm{~F} / \mathrm{E}, \mathrm{Ab} / \mathrm{Ad}$ \\
\hline & 2008 & $\begin{array}{l}\text { Balasubramanian et al. } \\
\text { (2008) }\end{array}$ & Pneumatic & McKibben & Bending & 2 & $\mathrm{E}, \mathrm{Su}$ \\
\hline & 2017 & Lessard et al. (2017) & $\begin{array}{l}\text { Cable- } \\
\text { driven }\end{array}$ & $\begin{array}{l}\text { Bowden } \\
\text { cables }\end{array}$ & Tensile & 1 & $\mathrm{Su} / \mathrm{Pr}$ \\
\hline & 2017 & Hassanin et al. (2017) & Pneumatic & McKibben & Bending & 1 & $\begin{array}{r}\mathrm{Ab} / \mathrm{Ad} \\
\mathrm{Su} / \mathrm{Pr}\end{array}$ \\
\hline & - & - & - & - & Contraction & 1 & $\mathrm{Ab} / \mathrm{Ad}$ \\
\hline & 2017 & Zhu et al. (2017) & Pneumatic & Textile/fabric & Bending & 1 & $\mathrm{~F} / \mathrm{E}$ \\
\hline & 2018 & Lessard (2018) & $\begin{array}{l}\text { Cable- } \\
\text { driven }\end{array}$ & $\begin{array}{l}\text { Bowden } \\
\text { cables }\end{array}$ & Tensile & 1 & $\mathrm{Su} / \mathrm{Pr}$ \\
\hline & 2018 & Li et al. (2018) & $\begin{array}{l}\text { Cable- } \\
\text { driven }\end{array}$ & $\begin{array}{r}\text { Bowden } \\
\text { cables }\end{array}$ & Tensile & 1 & $\mathrm{Su} / \mathrm{Pr}$ \\
\hline & 2019 & Ang and Yeow (2019) & Pneumatic & Elastomeric & Rotary & 1 & $\mathrm{~F} / \mathrm{E}, \mathrm{Su} / \mathrm{Pr}$ \\
\hline & 2019 & Park et al. (2019b) & Pneumatic & Textile/fabric & Contraction & 1 & $\mathrm{Su} / \mathrm{Pr}$ \\
\hline & 2019 & Realmuto and Sanger (2019) & Pneumatic & Textile/fabric & $\begin{array}{l}\text { Bending/ } \\
\text { curling }\end{array}$ & 1 & $\mathrm{Su} / \mathrm{Pr}$ \\
\hline \multirow[t]{22}{*}{ e. Hand } & 2004 & Noritsugu et al. (2004) & Pneumatic & McKibben & Bending & 1 & $\mathrm{~F}$ \\
\hline & - & - & Pneumatic & McKibben & Extension & 1 & $\mathrm{E}$ \\
\hline & 2008 & Noritsugu et al. (2008) & Pneumatic & Textile/fabric & Bending & 1 & $\mathrm{~F}$ \\
\hline & 2012 & Nilsson et al. (2012) & $\begin{array}{l}\text { Cable- } \\
\text { driven }\end{array}$ & $\begin{array}{l}\text { Bowden } \\
\text { cables }\end{array}$ & Tensile & 1 & $\mathrm{~F}$ \\
\hline & 2014 & Lee et al. (2014) & $\begin{array}{l}\text { Cable- } \\
\text { driven }\end{array}$ & Tendons & Tensile & 1 & $\mathrm{~F} / \mathrm{E}$ \\
\hline & 2015 & Yap et al. (2015b) & Pneumatic & Elastomeric & Rotary & 1 & $\mathrm{~F}$ \\
\hline & 2015 & Yap et al. (2015a) & Pneumatic & Elastomeric & Bending & 1 & $\mathrm{~F} / \mathrm{E}$ \\
\hline & 2015 & In et al. (2015) & $\begin{array}{l}\text { Cable- } \\
\text { driven }\end{array}$ & $\begin{array}{r}\text { Bowden } \\
\text { cables }\end{array}$ & Tensile & 1 & $\mathrm{~F} / \mathrm{E}$ \\
\hline & 2015 & Nycz et al. (2015) & $\begin{array}{l}\text { Cable- } \\
\text { driven }\end{array}$ & $\begin{array}{r}\text { Bowden } \\
\text { cables }\end{array}$ & Tensile & 1 & $\mathrm{~F} / \mathrm{E}$ \\
\hline & 2015 & Polygerinos et al. (2015) & Pneumatic & Elastomeric & Bending & 1 & $\mathrm{~F}$ \\
\hline & 2016 & Borboni et al. (2016) & $\begin{array}{l}\text { Cable- } \\
\text { driven }\end{array}$ & $\begin{array}{l}\text { Bowden } \\
\text { cables }\end{array}$ & Tensile & 1 & $\mathrm{~F}$ \\
\hline & 2016 & Zhao et al. (2016) & Pneumatic & Elastomeric & Tensile & 1 & $\mathrm{~F} / \mathrm{E}$ \\
\hline & 2017 & Meeker et al. (2017) & $\begin{array}{l}\text { Cable- } \\
\text { driven }\end{array}$ & $\begin{array}{l}\text { Bowden } \\
\text { cables }\end{array}$ & Tensile & 1 & $\mathrm{E}$ \\
\hline & 2017 & Xiloyannis et al. (2017) & $\begin{array}{l}\text { Cable- } \\
\text { driven }\end{array}$ & $\begin{array}{r}\text { Bowden } \\
\text { cables }\end{array}$ & Tensile & 1 & $\mathrm{~F} / \mathrm{E}$ \\
\hline & 2018 & Cappello et al. (2018b) & Pneumatic & Textile/fabric & Bending & 1 & $\mathrm{~F} / \mathrm{E}$ \\
\hline & 2018 & Kang et al. (2018) & $\begin{array}{l}\text { Cable- } \\
\text { driven }\end{array}$ & $\begin{array}{l}\text { Bowden } \\
\text { cables }\end{array}$ & Tensile & 1 & $\mathrm{~F} / \mathrm{E}$ \\
\hline & 2018 & Park et al. (2018) & $\begin{array}{l}\text { Cable- } \\
\text { driven }\end{array}$ & $\begin{array}{r}\text { Bowden } \\
\text { cables }\end{array}$ & Tensile & 1 & $\mathrm{E}$ \\
\hline & 2018 & Jiang et al. (2018) & Pneumatic & Elastomeric & Bending & 1 & $\mathrm{E}$ \\
\hline & 2019 & Heung et al. (2019) & Pneumatic & Elastomeric & Rotary & 1 & $\mathrm{~F} / \mathrm{E}$ \\
\hline & 2019 & Shiota et al. (2019) & Pneumatic & Elastomeric & Bending & 1 & $\mathrm{~F}$ \\
\hline & 2019 & Heung et al. (2019) & Pneumatic & Elastomeric & Bending & 1 & $\mathrm{~F}$ \\
\hline & 2019 & Zhang et al. (2019a) & Pneumatic & Elastomeric & Stiffening & 1 & $\mathrm{~F}$ \\
\hline \multirow[t]{9}{*}{ f. } & & Thumb & 2004 & $\begin{array}{c}\text { Noritsugu et } \\
\text { al. (2004) }\end{array}$ & Pneumatic & & McKibben \\
\hline & & Contraction & & $\mathrm{Ab} / \mathrm{Ad}$ & & & \\
\hline & & & 1 & & & & \\
\hline & 2010 & Connelly et al. (2010) & Pneumatic & Textile/fabric & Bending & 1 & Ad \\
\hline & 2014 & Maeder-York et al. (2014) & Pneumatic & Elastomeric & Bending & 1 & $\mathrm{~F}$ \\
\hline & 2014 & Lee et al. (2014) & $\begin{array}{l}\text { Cable- } \\
\text { driven }\end{array}$ & $\begin{array}{l}\text { Bowden } \\
\text { cables }\end{array}$ & Tensile & 1 & $\mathrm{Ab} / \mathrm{Ad}$ \\
\hline & 2015 & Yap et al. (2015a) & Pneumatic & Elastomeric & Bending & 1 & $\mathrm{Ab}$ \\
\hline & 2018 & Kim and Park et al. (2018) & $\begin{array}{l}\text { Cable- } \\
\text { driven }\end{array}$ & $\begin{array}{l}\text { Bowden } \\
\text { cables }\end{array}$ & Tensile & 1 & $\mathrm{Ab} / \mathrm{Ad}$ \\
\hline & 2019 & Shiota et al. (2019) & Pneumatic & Elastomeric & Bending & 1 & $\mathrm{Ab} / \mathrm{Ad}$ \\
\hline
\end{tabular}


multiple joints. Figure 6 shows a few of these devices. Tables 3 and 4 provide a comprehensive list of referenced work, specifying the works observed for each section and joint location for assistance.

\subsection{Hip}

The human hip is a critical joint that allows for the transmission of force from the grown to the torso. The hips also assist in standing, balancing, postural, and sitting tasks, and hip joint actuation with SWRs (shown in Table $3 \mathrm{~g}$ ) primarily relies on cable-driven actuation, due to the high torque output from the

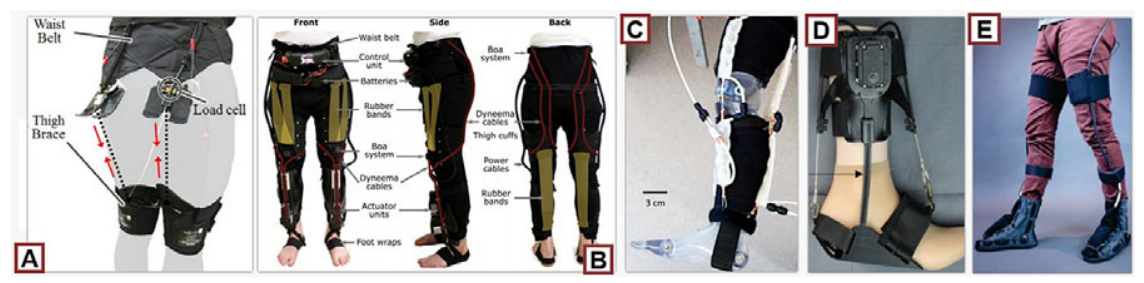

Figure 6. A brief survey of lower body soft wearable robots (SWRs), focused on each joint listed in "UB soft assistive robotics" section. (a) Shows an exosuit developed by the Wyss Institute to support the hip (Lee et al. 2017a). (b) Shows an exosuit with a combination of cables and passive elastic bands used to assist the hip and knee joints (Schmidt et al. 2017). (c) Provides an example of a soft knee exosuit using elastomeric pneumatic artificial muscles (PAMs) (Park et al. 2014b), (d) an ankle device using cabledriven mechanisms to support multiple degrees of freedom from Carnegie Mellon University (Kwon et al.

2019), and (e) shows the ExoBoot, which uses fabric-based inflatables for ankle plantarflexion

(Chung et al. 2018).

Table 3. This table lists of some of the most cited and prevalent works in soft wearable robots (SWRs) for the lower body over the past decade, focused on the hip and knee joint.

\begin{tabular}{|c|c|c|c|c|c|c|c|}
\hline Joint & Year & Soft wearable robot & Actuation & Method & Design & DoF & Motion \\
\hline \multirow[t]{17}{*}{ g. Hip } & 2013 & Wehner et al. (2013) & Pneumatic & McKibben & Contraction & 1 & $\mathrm{~F} / \mathrm{E}$ \\
\hline & 2013 & Kawamura et al. (2013) & Pneumatic & McKibben & Contraction & 1 & $\mathrm{~F}$ \\
\hline & 2015 & Asbeck et al. (2015c) & Cable-driven & Bowden cables & Tensile & 1 & $\mathrm{E}$ \\
\hline & 2015 & Quinlivan et al. (2015) & Cable-driven & Bowden cables & Tensile & 1 & $\mathrm{E}$ \\
\hline & 2015 & Asbeck et al. (2015a) & Cable-driven & Bowden cables & Tensile & 1 & $\mathrm{~F}$ \\
\hline & 2015 & Wu et al. (2015) & Cable-driven & Bowden cables & Tensile & 1 & $\mathrm{~F}$ \\
\hline & 2016 & Lee et al. (2016) & Cable-driven & Bowden cables & Tensile & 1 & $\mathrm{~F}$ \\
\hline & 2016 & Ding et al. (2016) & Cable-driven & Bowden cables & Tensile & 1 & $\mathrm{E}$ \\
\hline & 2017 & Schmidt et al. (2017) & Cable-driven & Bowden cables & Tensile & 1 & $\mathrm{E}$ \\
\hline & 2017 & Ding et al. (2017) & Cable-driven & Bowden cables & Tensile & 1 & $\mathrm{~F}$ \\
\hline & 2017 & Karavas et al. (2017) & Cable-driven & Bowden cables & Tensile & 1 & $\mathrm{~F}$ \\
\hline & 2018 & Thakur et al. (2018) & Pneumatic & Elastomeric & Contraction & 1 & $\mathrm{~F}$ \\
\hline & 2018 & Poliero et al. (2018) & Cable-driven & Bowden cables & Tensile & 1 & $\mathrm{E}$ \\
\hline & 2019 & Di Natali et al. (2019) & Cable-driven & Bowden cables & Tensile & 1 & $\mathrm{E}$ \\
\hline & 2019 & Park et al. (2019a) & Cable-driven & Bowden cables & Tensile & 1 & $\mathrm{E}$ \\
\hline & 2019 & Panizzolo et al. (2019) & Cable-driven & Bowden cables & Tensile & 1 & $\mathrm{E}$ \\
\hline & 2019 & Fraiszudeen and Yeow (2019) & Pneumatic & Textile/fabric & Tensile & 1 & $\mathrm{E}$ \\
\hline \multirow[t]{10}{*}{ h. Knee } & 2012 & Teng et al. (2012) & Pneumatic & McKibben & Contraction & 1 & $\mathrm{~F} / \mathrm{E}$ \\
\hline & 2013 & Wehner et al. (2013) & Pneumatic & McKibben & Contraction & 1 & $\mathrm{~F}$ \\
\hline & 2013 & Baiden and Ivlev (2013) & Pneumatic & McKibben & Contraction & 1 & $\mathrm{~F}$ \\
\hline & 2014 & Park et al. (2014b) & Pneumatic & Elastomeric & Contraction & 1 & $\mathrm{E}$ \\
\hline & 2017 & (Schmidt et al. 2017) & Cable-driven & Bowden cables & Tensile & 1 & $\mathrm{E}$ \\
\hline & 2018 & Thakur et al. (2018) & Pneumatic & Elastomeric & Contraction & 1 & $\mathrm{E}$ \\
\hline & 2019 & (Park et al. 2019a) & Cable-driven & Bowden cables & Tensile & 1 & $\mathrm{E}$ \\
\hline & 2019 & Miller-Jackson et al. (2019c) & Pneumatic & Textile/fabric & Rotary & 1 & $\mathrm{E}$ \\
\hline & 2019 & Fraiszudeen and Yeow (2019) & Pneumatic & Textile/fabric & Stiffening & 1 & $\mathrm{E}$ \\
\hline & 2019 & Ezzibdeh et al. (2019) & Pneumatic & Textile/fabric & Rotary & 1 & $\mathrm{E}$ \\
\hline
\end{tabular}

Each research group included below has been sorted by the joint assisted and actuation method used.

Abbreviations: Ab, abduction; Ad, adduction; E, extension; F, flexion; Su, supination; Pr, pronation. 
Table 4. This table is a continuation of the previous table for soft wearable robots (SWRs) for assisting the lower body, detailing work done on the ankle joint.

\begin{tabular}{|c|c|c|c|c|c|c|c|}
\hline Joint & Year & Soft wearable robot & Actuation & Method & Design & DoF & Motion \\
\hline \multirow[t]{30}{*}{ i. Ankle } & 2006 & Gordon et al. (2006) & Pneumatic & McKibben & Contraction & 1 & $\mathrm{P}$ \\
\hline & 2006 & Ferris et al. (2006) & Pneumatic & McKibben & Contraction & 1 & $\mathrm{D} / \mathrm{P}$ \\
\hline & 2011 & Park et al. (2011) & Pneumatic & McKibben & Contraction & 2 & $\mathrm{P}, \mathrm{I} / \mathrm{E}$ \\
\hline & 2012 & Teng et al. (2012) & Pneumatic & McKibben & Contraction & 1 & $\mathrm{D} / \mathrm{P}$ \\
\hline & 2012 & Wehner et al. (2012) & Cable-driven & Bowden cables & Tensile & 1 & $\mathrm{P}$ \\
\hline & 2013 & Asbeck et al. (2013) & Cable-driven & Bowden cables & Tensile & 1 & $\mathrm{P}$ \\
\hline & 2013 & Wehner et al. (2013) & Pneumatic & McKibben & Contraction & 1 & $\mathrm{D} / \mathrm{P}$ \\
\hline & 2014 & Murphy et al. (2014) & Pneumatic & McKibben & Contraction & 2 & $\mathrm{D} / \mathrm{P}, \mathrm{I} / \mathrm{E}$ \\
\hline & 2014 & Park et al. (2014a) & Pneumatic & McKibben & Contraction & 2 & $\mathrm{D} / \mathrm{P}, \mathrm{I} / \mathrm{E}$ \\
\hline & 2015 & Bae et al. (2015) & Cable-driven & Bowden cables & Tensile & 1 & $\mathrm{D} / \mathrm{P}$ \\
\hline & 2015 & Low et al. (2015) & Pneumatic & Elastomeric & Contraction & 1 & $\mathrm{D}$ \\
\hline & 2015 & Asbeck et al. (2015a) & Cable-driven & Bowden cables & Tensile & 1 & $\mathrm{P}$ \\
\hline & 2016 & Low et al. (2016) & Pneumatic & Elastomeric & Contraction & 1 & $\mathrm{D}$ \\
\hline & 2016 & Sovero et al. (2016) & Pneumatic & Textile/fabric & Rotary & 1 & $\mathrm{P}$ \\
\hline & 2016 & Lee et al. (2016) & Cable-driven & Bowden cables & Tensile & 1 & $\mathrm{D} / \mathrm{P}$ \\
\hline & 2017 & Awad et al. (2017b) & Cable-driven & Bowden cables & Tensile & 1 & $\mathrm{D} / \mathrm{P}$ \\
\hline & 2017 & Ding et al. (2017) & Cable-driven & Bowden cables & Tensile & 1 & $\mathrm{P}$ \\
\hline & 2017 & Yandell et al. (2017) & Cable-driven & Bowden cables & Tensile & 1 & $\mathrm{P}$ \\
\hline & 2017 & Siviy et al. (2017) & Cable-driven & Bowden cables & Tensile & 1 & $\mathrm{P}$ \\
\hline & 2017 & Karavas et al. (2017) & Cable-driven & Bowden cables & Tensile & 1 & $\mathrm{P}$ \\
\hline & 2017 & Hong et al. (2017) & Pneumatic & McKibben & Contraction & 1 & $\mathrm{P}$ \\
\hline & 2017 & Bowers et al. (2017) & Pneumatic & McKibben & Contraction & 1 & $\mathrm{D} / \mathrm{P}$ \\
\hline & 2018 & Chung et al. (2018) & Pneumatic & Textile/fabric & Stiffening beam & 1 & $\mathrm{P}$ \\
\hline & 2018 & Iwata et al. (2018) & Pneumatic & McKibben & Contraction & 1 & $\mathrm{D}$ \\
\hline & 2019 & Thalman et al. (2019) & Pneumatic & Textile/fabric & Contraction & 1 & $\mathrm{D}$ \\
\hline & 2019 & Di Natali et al. (2019) & Cable-driven & Bowden cables & Tensile & 1 & $\mathrm{D} / \mathrm{P}$ \\
\hline & 2019 & Kwon et al. (2019) & Cable-driven & Bowden cables & Tensile & 1 & $\mathrm{D} / \mathrm{P}$ \\
\hline & 2019 & Zhang et al. (2019b) & Pneumatic & McKibben & Contraction & 1 & $\mathrm{D} / \mathrm{P}$ \\
\hline & 2020 & Thalman et al. (2020) & Pneumatic & Textile/fabric & Contraction & 1 & $\mathrm{P}$ \\
\hline & 2020 & Thalman and Lee (2020) & Pneumatic & Textile/fabric & Stiffening beam & 1 & $\mathrm{I} / \mathrm{E}$ \\
\hline
\end{tabular}

This is another heavily researched area and the worked cited below are some of the most well-known and exemplary works sorted by the assisted degree of freedom and actuation method used.

Abbreviations: D, dorsiflexion; E, eversion; I, inversion; P, plantarflexion.

tension forces of the cables as shown in (Wu et al. 2015; Asbeck et al. 2015c; Ding et al. 2016; Lee et al. 2017a; Ding et al. 2018; Di Natali et al. 2019), though recent work has shown how fluidic actuators done by groups (Kawamura et al. 2013; Thakur et al. 2018) and passive actuation methods seen in (Lee et al. 2017b) can be used in hip assistance. Hip assistance from SWRs can be used for both stationary sit-tostand tests or during corrective gait therapy (Abouhossein et al. 2018; Fraiszudeen and Yeow 2019).

\subsection{Knee}

SWRs have been designed to help assist in both knee flexion and extension, as well as to provide stability to the knee joint to prevent buckling at the knee as shown in Table $3 \mathrm{~h}$. SWRs for the knee are often seen as stationary systems designed to be worn to address issues with gait symmetry (Elliott et al. 2013). This can be done by assisting the knee in either flexion or extension for executing the swing phase or providing support during the weight shift in the stance phase (Teng et al. 2012). Many designs are cable-driven systems that pull the knee into both flexion and extension (Asbeck et al. 2013; Di Natali et al. 2019). Other research has been done on using fluidic actuators for knee assistance (Teng et al. 2012; Park et al. 2014b; Ezzibdeh et al. 2019; Miller-Jackson et al. 2019c). Issues with pneumatic knee assistance are found in the latency in the actuators firingas mentioned in reference to pneumatic control. Other methods of actuation include passive elastic elements to provide preventative microcorrections (Elliott et al. 2013).

\subsection{Ankle and foot}

Prior to advancements in portable, wearable robotics, most ankle rehabilitation robots focused on seated therapies on robotic platforms that would adjust or orient the ankle into various positions (Table 4i). 
Designing wearable robots for the ankle joint has been difficult until recent years, as rigid robots can be heavy and adding excessive weight to the ankle joint can lead to increased risk of trips or slowed gait due to higher inertia at the foot while walking (Browning et al. 2007). The ankle joint has two major degrees of freedom, the dorsiflexion/plantarflexion (DP) axis and the inversion/eversion (IE) axis (Hong et al. 2017; Perez-Ibarra et al. 2017). During walking, the DP axis plays a major role in assisting in forward locomotion and foot ground clearance (toe up and toe down), while IE assists in ankle stability and resilience to external perturbations during movement (lateral ankle rotation) (Hong et al. 2017; Siviy et al. 2017).

A few early instances of soft actuators seen for ankle rehabilitation consisted of a McKibben actuator affixed to a rigid orthosis. Issues with latency and weight were still prevalent, however, and as more opportunities became available with DARPA and other funding sources, there was a noticeable shift toward one of the most common approaches for SWRs for the ankle: Cable-driven systems or other forms of contracting actuation methods have been widely seen in use ankle assistance, likely due to similarities with the tendon and muscle groups that control the foot (Park et al. 2011; Ren et al. 2017; Iwata et al. 2018). This can be attributed to the high complexity and torque requirements for the ankle joint, specifically plantarflexion, during walking (Teng et al. 2012; Murphy et al. 2014; Chung et al. 2018). There is extensive research on using cable-driven systems to assist ankle function, both through calculated torque generation and metabolic cost reduction experimentation (Chin et al. 2009; Chung et al. 2018; Yandell et al. 2019). Cable-driven ankle SWRs tend to switch between both assistance and augmentation, with applications ranging from warfighter assistance to poststroke rehabilitation during walking (Bae et al. 2015; Sovero et al. 2016; Siviy et al. 2017; Kwon et al. 2019). Fluidic actuation methods for the ankle are relatively popular, with some of the most notable contributions using PAM Mckibben-type actuators (Wehner et al. 2012; Murphy et al. 2014; Sovero et al. 2016; Bowers et al. 2017), with a select few fabric-based inflatable devices (Chung et al. 2018; Thalman et al. 2019; Thalman and Lee 2020). Some applications seek simply to add stability and prevent trips and falls using the user's body weight to distribute pressure through different chambers based on where the user is applying their body weight to their foot (Babu et al. 2018).

\section{Discussion}

This review presents an examination of SWR devices for human assistance. A survey of actuation methods used in wearable devices, fabrication advancements, and applications is presented to provide a comprehensive overview of trends with the field. Soft robotics is an effective approach to providing wearable robotic technologies with lightweight, low cost, and comfortable adaptations, while pushing the boundaries of material science and sensing technology. The rapidly growing field is challenging the way that roboticists have thought about wearable assistive devices and is providing new pathways to enabling users to have wearable assistive robotics that are nearly transparent to their movement.

Soft robotic actuators have many benefits; however, there are areas where improvements are still needed to further enhance the field. Potential areas for growth and current issues that are seen across most wearable robots in general are the power sources for actuation. Pneumatic systems require some method of obtaining pressurized fluid to perform actuation, which is usually done by tethering the SWR to a compressor and regulating the resulting output pressure (Sasaki et al. 2005b; Ding et al. 2014; Wang 2016). The ideal system would be a standalone electropneumatic system, giving the user unconstrained mobility (Manfredi and Cuschieri 2019); however, portable pneumatic sources typically have struggled to provide sufficient flow rate or volume for most adult users without excessive weight (Wehner et al. 2012; Thalman et al. 2018). Latency issues resulting from pneumatic power sources is common in soft robotics (Malcolm et al. 2013). This can be mitigated somewhat with the higher flow rates that can be achieved from directly connecting to air supply lines in existing infrastructure or tubing with larger diameter (Ding et al. 2014). Cable-driven systems use battery-powered motors and control boards to induce actuation, which can be easily implemented into a hip-mounted pouch or a backpack to house all control components (Bae et al. 2015). Actuation motors are commonly mounted on the body to ensure the cables remain routed along the path needed to produce desired torques. While advantageous to have all hardware easily portable, a disadvantage is that the weight is often borne by the user. 
The compliant and extremely variable positioning and behaviors of materials used in many SWRs can cause difficulties when higher levels of flexibility are introduced to the core foundation of the device. Control of compliant actuation methods is usually based on oversimplified models based on pressure, volume, simplified geometries, constant-curvature, or basic deformation (Petersen and Shepherd 2018). While cable-driven system control has been more widely investigated, control of fluidic or extremely compliant actuator bodies has created interest in the soft robotics community posed as a free-form, openended question: How can soft-bodied actuators be controlled? Open loop control is often times not sufficient, and so closed loop control is attempted using these simplified models. Bang-bang control is a common control strategy, using pressure or bending/curvature sensors to trigger pressurization at defined intervals (Petersen and Shepherd 2018). Modern sensing technology is shifting toward integrating sensing capabilities into fabric-based actuators or into the fabric itself. By mimicking clothing, these garment-like sensors are less cumbersome and invasive to the user. Strain-gauge goniometers and flexible resistive sensors can be used to measure the body's displacement directly and are a popular method of collecting data of actuator positioning and behavior (Mengüç et al. 2014; Park et al. 2014a; Porciuncula et al. 2018; Kim et al. 2019). Incorporating Inertial Measurement Units (IMUs) is another common approach to collecting accurate data on the real-time positioning of a specified point on the user or exosuit (Karavas et al. 2017; Abouhossein et al. 2018). Muscle activity can be also used to trigger the wearable device at certain intervals where surface mount electromyography (sEMG) sensors are used to monitor the electrical potential of the user's muscles (Ferris et al. 2006; Porciuncula et al. 2018). Force-sensitive resistors (FSRs) are used frequently for LB wearables devices and can be embedded in soft silicone insoles worn by the user to track weight distribution on certain regions of the foot (Poliero et al. 2018; Porciuncula et al. 2018).

Soft robotics poses as a safe method to provide robotic assistance to individuals who may have unpredictable behaviors or movements patterns, without a noticeable amount of weight or bulk (Polygerinos et al. 2017). LB-assistive robotics are typically focused on gait training, restoring some form of symmetry to an otherwise abnormal gait pattern, or offloading muscle effort for a gait with reduced strain to the user (Kawamura et al. 2013). These exosuits can be used to actively prevent compensatory gait mechanics, provide additional support and stiffness, or encourage proper gait mechanics (Abouhossein et al. 2018). Some assistive devices, especially those focused on UB systems and the hand, aim to help impaired user regain independence and achieve ADL (Morales et al. 2011; Maciejasz et al. 2014). With preventative assistance, SWRs alleviate strain to particular parts of the body by offloading or translating pressure and stress from the user. This can help prevent injuries caused by heavy lifting, repetitive tasks, and poor ergonomics. Human augmentation can be achieved with wearable devices by providing high amounts of torque and force, while some SWRs can assist users carrying extremely heavy loads over long distances, lift at higher capacities, run faster with a lower metabolic cost, and even increase sports performance (Roam 2009; Lee et al. 2017a).

Review of existing SWRs presented in this manuscript shows a trend that is beginning to favor actuator designs that can be easily embedded into the user's clothing with minimal interference to normal RoM and increased comfort. Observations from current devices and prevalence in the field based on publication records suggest that assistive soft robots are still in their infancy. This leaves ample opportunity for the field to begin to further explore how fabric-based actuators can be integrated together with other efforts toward functional garments to advance the way that rehabilitative robotics is approached for UB and LB assistance.

Funding Statement. Thalman is funded by the National Science Foundation, Graduate Research Fellowship Program (NSFGRFP). This material is based upon work supported by the National Science Foundation under Grants No. \#2020009 and \#2025797.

Competing Interests. The authors declare no competing interests exist.

Authorship Contributions. Conceptualization, C.T; Data curation, C.T. and P.A.; Data visualization, C.T.; Writing-original draft, C.T. and P.A. All authors approved the final submitted draft.

Ethical Standards. The research meets all ethical guidelines, including adherence to the legal requirements of the study country. 


\section{References}

Abe T, Koizumi S, Nabae H, Endo G and Suzumori K(2018) Muscle textile to implement soft suit to shift balancing posture of the body. In IEEE International Conference on Soft Robotics, (RoboSoft), 24-28 April 2018, Livorno, Italy, 572-578.

Abe T, Koizumi S, Nabae H, Endo G, Suzumori K, Sato N, Adachi M and Takamizawa F (2019) Fabrication of "18 Weave" muscles and their application to soft power support suit for upper limbs using thin McKibben muscle. IEEE RA-L, International Conference on Soft Robotics (RoboSoft) 4(3), 2532-2538.

Abouhossein A, Martinez-Hernandez U, Awad MI and Dehghani-Sanij AA (2018) Human-activity-centered measurement system: Challenges from laboratory to the real environment in assistive gait wearable robotics. In Mechatronics 2018Reinventing Mechatronics, 16th Mechatronics Forum International Conference.

Abrar T, Putzu F, Konstantinova J and Althoefer K (2019) EPAM: Eversive pneumatic artificial muscle. In IEEE International Conference on Soft Robotics, (RoboSoft), pp. 2-7.

Ang BWK and Yeow C (2019) Design and characterization of a 3D printed soft robotic wrist sleeve with 2 DoF for stroke rehabilitation. In IEEE International Conference on Soft Robotics (RoboSoft).

Aragane M, Noritsugu T, Takaiwa M, Sasaki D. and Naomoto S (2008) Development of sheet-like curved type pneumatic rubber muscle and application to elbow power assist wear. JRSJ 26(6), 206-214.

Asbeck A, Dyer R, Larusson A and Walsh C (2013) Biologically-inspired soft exosuit. In 2013 IEEE 13th International Conference on Rehabilitation Robotics (ICORR), pp. 1-8.

Asbeck AT, De Rossi SM, Galiana I, Ding Y and Walsh CJ (2014) Stronger, smarter, softer: Next-generation wearable robots. IEEE Robotics \& Automation Magazine 21(4), 22-33.

Asbeck AT, De Rossi SM, Holt KG and Walsh CJ (2015a) A biologically inspired soft exosuit for walking assistance. International Journal of Robotics Research, vol. 34, no. 6, pp. 744-762.

Asbeck AT, Schmidt K, Galiana I, Wagner D and Walsh CJ (2015b) Multi-joint soft exosuit for gait assistance. Proceedings of IEEE International Conference on Robotics and Automation 2015, 6197-6204.

Asbeck AT, Schmidt K and Walsh CJ (2015c) Soft exosuit for hip assistance. Robotics and Autonomous Systems 73, $102-110$.

Awad LN, Bae J, Kudzia P, Long A, Hendron K, Holt KG, O'Donnell K, Ellis TD and Walsh CJ (2017a) Reducing circumduction and hip hiking during hemiparetic walking through targeted assistance of the paretic limb using a soft robotic exosuit. American Journal of Physical Medicine \& Rehabilitation, 96 (10 Suppl 1): S157-S164.

Awad LN, Bae J, O'donnell K, De Rossi SM, Hendron K, Sloot LH, Kudzia P, Allen S, Holt KG, Ellis TD and Walsh C (2017b) A soft robotic exosuit improves walking in patients after stroke. Science Translational Medicine 9(400), eaai9084.

Babic $^{`}$ J, Mombaur K, Lefeber D, van Dieën J, Graimann B, Russold M, Šarabon N and Houdijk H (2017) Spexor: Spinal exoskeletal robot for low back pain prevention and vocational reintegration. In Wearable Robotics: Challenges and Trends. Biosystems \& Biorobotics, vol. 16. Springer, Cham. pp. 311-315.

Babu SP, Sadeghi A, Mondini A and Mazzolai B (2018) Soft sucker shoe for anti-slippage application. In IEEE International Conference on Soft Robotics, (RoboSoft). IEEE, pp. 491-496.

Bae J, De Rossi SMM, O’Donnell K, Hendron KL, Awad LN, Teles Dos Santos TR, De Araujo VL., Ding Y, Holt KG, Ellis TD and Walsh CJ (2015) A soft exosuit for patients with stroke: Feasibility study with a mobile off-board actuation unit. In IEEE International Conference on Rehabilitation Robotics. IEEE, pp. 131-138.

Baiden D and Ivlev O (2013) Human-robot-interaction control for orthoses with pneumatic soft-actuators - Concept and initial trails. IEEE 13th International Conference on Rehabilitation Robotics (ICORR), 2013 Jun 24 (pp. 1-6).

Balasubramanian S, Wei, HR, Perez M, Shepard B, Koeneman E, Koeneman J and He J (2008) Rupert: An exoskeleton robot for assisting rehabilitation of arm functions. In 2008 Virtual Rehabilitation. IWVR, pp. 163-167.

Baltrusch, SJ, van Dieën JH, van Bennekom CA and Houdijk H (2018) The effect of a passive trunk exoskeleton on functional performance in healthy individuals. Applied Ergonomics 72, 94-106.

Bao G, Fang H, Chen L, Wan Y, Xu F, Yang Q and Zhang L (2018) Soft robotics: Academic insights and perspectives through bibliometric analysis. Soft Robotics 5(3), 229-241.

Bilodeau RA, Miriyev A, Lipson H and Kramer-Bottiglio R (2018) All-soft material system for strong soft actuators. In IEEE International Conference on Soft Robotics, (RoboSoft), pp. 288-294.

Borboni A, Mor M and Faglia R (2016) Gloreha - hand robotic rehabilitation: Design, mechanical model, and experiments. Journal of Dynamic Systems, Measurement, and Control 138(11): 111003.

Bowers MP, Harmalkar CV, Agrawal A, Kashyap A, Tai J and Popovic M (2017) Design and test of biologically inspired multifiber Hydro Muscle actuated ankle. In Proceedings of IEEE Workshop on Advanced Robotics and its Social Impacts, ARSO.

Browning RC, Modica JR, Kram R and Goswami A (2007) The effects of adding mass to the legs on the energetics and biomechanics of walking. Medicine \& Science in Sports \& Exercise 39(3), 515-525.

Cappello L, Galloway KC, Sanan S, Wagner DA, Granberry R, Engelhardt S, Haufe FL, Peisner JD and Walsh CJ (2018a) Exploiting textile mechanical anisotropy for fabric-based pneumatic actuators. Soft Robotics 5(5), 662-674.

Cappello L, Meyer JT, Galloway KC, Peisner JD, Granberry R, Wagner DA, Engelhardt S, Paganoni S and Walsh CJ (2018b) Assisting hand function after spinal cord injury with a fabric-based soft robotic glove. Journal of NeuroEngineering and Rehabilitation 15(1), 1-10.

Chiaradia D, Xiloyannis M, Antuvan CW, Frisoli A and Masia L (2018) Design and embedded control of a soft elbow exosuit. In IEEE International Conference on Soft Robotics, (RoboSoft), pp. 565-571. 
Chin R, Hsiao-Wecksler ET, Loth E, Kogler G, Manwaring SD, Tyson SN, Shorter KA and Gilmer JN (2009) A pneumatic power harvesting ankle-foot orthosis to prevent foot-drop. Journal of NeuroEngineering and Rehabilitation, 6, Article number: 19.

Cho F, Sugimoto R, Noritsugu T and Li, X (2017) Improvement of wearable power assist wear for low back support using pneumatic actuator. In IOP Conference Series: Materials Science and Engineering, Vol. 249. IOP Publishing, p. 012004.

Chung J, Heimgartner R, Oneill CT, Phipps NS and Walsh CJ (2018) ExoBoot, a soft inflatable robotic boot to assist ankle during walking: Design, characterization and preliminary tests. In 2018 7th IEEE International Conference on Biomedical Robotics and Biomechatronics (Biorob). IEEE, pp. 509-516.

Cianchetti M, Laschi C, Menciassi A and Dario P(2018) Biomedical applications of soft robotics. Nature Reviews Materials 3(6), $143-153$.

Connelly L, Jia Y, Toro ML, Stoykov ME, Kenyon RV and Kamper DG (2010) A pneumatic glove and immersive virtual reality environment for hand rehabilitative training after stroke. IEEE Transactions on Neural Systems and Rehabilitation Engineering 18(5), 551-559.

Connolly F, Polygerinos P, Walsh CJ and Bertoldi K (2015) Mechanical programming of soft actuators by varying fiber angle. Soft Robotics 2(1), 26-32.

Connolly F, Wagner DA, Walsh CJ and Bertoldi K (2019) Sew-free anisotropic textile composites for rapid design and manufacturing of soft wearable robots. Extreme Mechanics Letters 27, 52-58.

Coyle S, Majidi C, LeDuc P and Hsia KJ (2018) Bio-inspired soft robotics: Material selection, actuation, and design. Extreme Mechanics Letters 22, 51-59.

Davis S, Tsagarakis N, Canderle J and Caldwell DG (2003) Enhanced modelling and performance in braided pneumatic muscle actuators. The International Journal of Robotics Research 22(3-4), 213-227.

Di Natali C, Poliero T, Sposito M, Graf E, Bauer C, Pauli C, Bottenberg E, De Eyto A, O'Sullivan L, Hidalgo AF, Scherly D, Stadler KS, Caldwell DG and Ortiz J (2019) Design and evaluation of a soft assistive lower limb exoskeleton. Robotica, Volume 37, Special Issue 12 1-21.

Ding Y, Galiana I, Asbeck AT, De Rossi SMM, Bae J, Santos T, De Araujo VL, Lee S, Holt KG and Walsh CJ (2017) Biomechanical and physiological evaluation of multi-joint assistance with soft exosuits. IEEE Transactions on Neural Systems and Rehabilitation Engineering 25(2), 119-130.

Ding Y, Galiana I, Siviy C, Panizzolo FA and Walsh CJ (2016) IMU-based iterative control for hip extension assistance with a soft exosuit. Proceedings of IEEE International Conference on Robotics and Automation 2016, 3501-3508.

Ding Y, Kim M, Kuindersma S and Walsh CJ (2018) Human-in-the-loop optimization of hip assistance with a soft exosuit during walking. Science Robotics, 28 Feb 2018:, Vol. 3, Issue 15.

Ding Y, Tolley MT, Park Y, Shepherd RF, Wood RJ, Wehner M, Mengüç Y, Mozeika A, Onal C and Whitesides GM (2014) Pneumatic energy sources for autonomous and wearable soft robotics. Soft Robotics, Volume: 1 Issue 4: December 23.

Dinh B, Xiloyannis M, Cappello L, Antuvan C, Yen S and Masia L (2017) Adaptive backlash compensation in upper limb soft wearable exoskeletons. Robotics and Autonomous Systems 92, 173-186.

Elliott G, Sawicki GS, Marecki A and Herr H (2013) The biomechanics and energetics of human running using an elastic knee exoskeleton. IEEE International Conference on Rehabilitation Robotics 0(4), 1-6.

Exoskeleton Report (ExR) (2020) Directory of exoskeleton developers. Available at https://exoskeletonreport.com/exoskeletoncompanies-and-organizations-directory/ (accessed April 2020).

Ezzibdeh R, Arora P and Amanatullah DF (2019) Utilization of a pneumatic exoskeleton after total knee arthroplasty. Arthroplasty Today, 5(3):314-315.

Felt W, Robertson MA and Paik J (2018) Modeling vacuum bellows soft pneumatic actuators with optimal mechanical performance. In IEEE International Conference on Soft Robotics, (RoboSoft), pp. 534-540.

Ferris DP, Gordon KE, Sawicki GS and Peethambaran A (2006) An improved powered ankle-foot orthosis using proportional myoelectric control. Gait and Posture 23(4), 425-428.

Fraiszudeen A and Yeow C (2019) Soft actuating sit-to-stand trainer seat. Journal of Mechanisms and Robotics 11(1), 014501.

Funabora Y (2018) Flexible fabric actuator realizing 3d movements like human body surface for wearable devices. In International Conference on Intelligent Robots and Systems (IROS), pp. 6992-6997.

Galiana I, Hammond FL, Howe RD and Popovic MB (2012) Wearable soft robotic device for post-stroke shoulder rehabilitation: Identifying misalignments. IEEE International Conference on Intelligent Robots and Systems, pp. 317-322.

Galloway KC, Polygerinos P, Walsh CJ and Wood RJ (2013) Mechanically programmable bend radius for fiber-reinforced soft actuators. In 2013 16th International Conference on Advanced Robotics (ICAR). IEEE, pp. 1-6.

Gao X, Sun Y, Hao L, Xiang C and Cheng H (2018) A new type of soft pneumatic elbow. 2017 IEEE International Conference on Robotics and Biomimetics, ROBIO 2017, 2018 January, pp. 2681-2686.

Gordon KE, Sawicki GS and Ferris DP (2006) Mechanical performance of artificial pneumatic muscles to power an ankle-foot orthosis. Journal of Biomechanics 39(10), 1832-1841.

Granberry Rand Duvall J, Dunne LE and Holschuh B (2017) An analysis of anthropometric geometric variability of the lower leg for the fit \& function of advanced functional garments. In Proceedings of the 2017 ACM International Symposium on Wearable Computers. ACM, pp. 10-17.

Han K, Kim N and Shin D (2018) A novel soft pneumatic artificial muscle with high-contraction ratio. Soft Robotics 5(5), 554-566.

Hassanin A, Steve D and Samia N (2017) A novel, soft, bending actuator for use in power assist and rehabilitation exoskeletons. In 2017 IEEE/RSJ International Conference on Intelligent Robots and Systems (IROS). IEEE, pp. 533-538. 
Heung KH, Tong RK, Lau AT and Li Z (2019) Robotic glove with soft-elastic composite actuators for assisting activities of daily living. Soft Robotics, 6(2):289-304.

Higuma T, Kiguchi K and Arata J (2017) Low-profile two-degree-of-freedom wrist exoskeleton device using multiple spring blade. IEEE Robotics and Automation Letters, pp. 1-1.

Hiramitsu T, Suzumori K, Nabae H and Endo G (2019) Experimental evaluation of textile mechanisms made of artificial muscles. In IEEE International Conference on Soft Robotics (RoboSoft).

Holland D, Park EJ, Polygerinos P, Bennett GJ and Walsh CJ (2014) The soft robotics toolkit: Shared resources for research and design. Soft Robotics 1(3), 224-230.

Holland DP, Abah C, Velasco-Enriquez M, Herman M, Bennett GJ, Vela E and Walsh CJ (2017) The Soft Robotics Toolkit: Strategies for Overcoming Obstacles to the Wide Dissemination of Soft-Robotic Hardware. IEEE Robotics and Automation Magazine., Vol. 24, pp 57-64

Hong J, Fukushima Y, Suzuki S, Yauda K, Ohashi H and Iwata H (2017) Estimation of ankle dorsiflexion torque during loading response phase for spring coefficient identification. In IEEE International Conference on Robotics and Biomimetics, pp. 2237-2242.

In H, Kang BB, Sin M and Cho K (2015) Exo-Glove: A wearable robot for the hand with a soft tendon routing system. IEEE Robotics and Automation Magazine 22(1), 97-105.

Inose H, Mohri S, Yamada Y, Nakamura T, Yokoyama K and Kikutani I (2016) Development of a lightweight power-assist suit using pneumatic artificial muscles and balloon-amplification mechanism. In 2016 14th International Conference on Control, Automation, Robotics and Vision (ICARCV). IEEE, pp. 1-6.

Irshaidat M, Soufian M, Al-Ibadi A and Nefti-Meziani S (2019) A novel elbow pneumatic muscle actuator for exoskeleton arm in post-stroke rehabilitation. In 2019 2nd IEEE International Conference on Soft Robotics (RoboSoft). IEEE, pp. 630-635.

Iwata H, Yasuda K, Hong J, Ohashi H, Suzuki S and Fukushima Y (2018) Development of high-dorsiflexion assistive robotic technology for gait rehabilitation. In IEEE International Conference on Systems, Man, and Cybernetics Development, pp. 3801-3806.

Jiang Y, Chen D, Liu P, Jiao X, Ping Z, Xu Z, Li J and Xu Y (2018) Fishbone-inspired soft robotic glove for hand rehabilitation with multi-degrees-of-freedom. In IEEE International Conference on Soft Robotics, (RoboSoft), pp. 394-399.

Kadivar Z, Beck C, Rovekamp R, O'Malley M and Joyce C (2017) On the efficacy of isolating shoulder and elbow movements with a soft, portable, and wearable robotic device. In Wearable Robotics: Challenges and Trends. Springer, pp. 89-93.

Kang BB, Choi H, Lee H and Cho K (2018) Exo-Glove poly II: A polymer-based soft wearable robot for the hand with a tendondriven actuation system. Soft Robotics, 0(0), soro.2018.0006.

Karavas N, Asbeck A, Galiana I, Wagner D, Siviy C, Grimmer M, Lee S, Quinlivan BT, Malcolm P, Walsh CJ and Rossi DM (2017) Assistance magnitude versus metabolic cost reductions for a tethered multiarticular soft exosuit. Science Robotics, Vol. 2 , Issue 2.

Kawamura T, Takanaka K, Nakamura T and Osumi H (2013) Development of an orthosis for walking assistance using pneumatic artificial muscle: A quantitative assessment of the effect of assistance. In 2013 IEEE 13th International Conference on Rehabilitation Robotics (ICORR). IEEE, pp. 1-6.

Kesner SB, Jentoft L, Hammond FL, Howe RD and Popovic M (2011) Design considerations for an active soft orthotic system for shoulder rehabilitation. In 2011 Annual International Conference of the IEEE Engineering in Medicine and Biology Society. IEEE, pp. 8130-8134.

Khin P, Yap H, Ang MH and Yeow C (2017) Fabric-based actuator modules for building soft pneumatic structures with high payload-to-weight ratio. IEEE International Conference on Intelligent Robots and Systems 2017, 2744-2750.

Kim D, Kim M, Kwon J, Park Y and Jo S (2019) Semi-supervised gait generation with two microfluidic soft sensors. IEEE Robotics and Automation Letters 4(3), 2501-2507.

Kim DH and Park H (2018) Cable actuated dexterous (cadex) glove for effective rehabilitation of the hand for patients with neurological diseases. In 2018 IEEE/RSJ International Conference on Intelligent Robots and Systems (IROS). IEEE, pp. 2305-2310.

Klute G, Czerniecki J and Hannaford B (1999) McKibben artificial muscles: pneumatic actuators with biomechanical intelligence. In IEEE/ASME International Conference on Advanced Intelligent Mechatronics, pp. 221-226.

Kobayashi H, Suzuki H and Iba M (2007) Development of a muscle suit for the upper limb motion support—A new shoulder mechanism and posture measurement. In 2006 World Automation Congress, WAC'06.

Koh T, Cheng N, Yap H and Yeow C (2017) Design of a soft robotic elbow sleeve with passive and intent-controlled actuation. Frontiers in Neuroscience 11, 1-12.

Koo I, Yun C, Costa MV, Scognamiglio JV, Yangali TA, Park D and Cho K (2014) Development of a meal assistive exoskeleton made of soft materials for polymyositis patients. In 2014 IEEE/RSJ International Conference on Intelligent Robots and Systems. IEEE, pp. 542-547.

Kwon J, Park J, Ku S, Jeong Y, Paik N and Park, Y. (2019) A soft wearable robotic ankle-foot-orthosis for post-stroke patients. IEEE RA-L, International Conference on Soft Robotics (RoboSoft).

Lamers EP, Yang AJ and Zelik KE (2018) Feasibility of a biomechanically-assistive garment to reduce low back loading during leaning and lifting. IEEE Transactions on Biomedical Engineering 65(8), 1674-1680. 
Lee G, Ding Y, Bujanda IG, Karavas N, Zhou YM and Walsh CJ (2017a) Improved assistive profile tracking of soft exosuits for walking and jogging with off-board actuation. In 2017 IEEE/RSJ International Conference on Intelligent Robots and Systems (IROS). IEEE, pp. 1699-1706.

Lee S, Crea S, Malcolm P, Galiana I, Asbeck A and Walsh C (2016) Controlling negative and positive power at the ankle with a soft exosuit. In IEEE International Conference on Robotics and Automation (ICRA). IEEE, pp. 3509-3515.

Lee SW, Landers KA and Park H (2014) Development of a biomimetic hand exotendon device (biomhed) for restoration of functional hand movement post-stroke. IEEE Transactions on Neural Systems and Rehabilitation Engineering 22(4), 886-898.

Lee Y, Roh S, Lee M, Choi B, Lee J, Kim J, Choi H, Shim Y and Kim Y (2017b) A flexible exoskeleton for hip assistance. IEEE International Conference on Intelligent Robots and Systems 2017, 1058-1063.

Lessard S, Pansodtee P, Robbins A, Baltaxe-Admony L, Trombadore JM, Teodorescu M, Agogino A and Kurniawan S (2017) CRUX: A compliant robotic upper-extremity exosuit for lightweight, portable, multi-joint muscular augmentation. IEEE International Conference on Rehabilitation Robotics 3, 1633-1638.

Lessard SR (2018) The Design, Consturction, and Evaluation of Crux: A Tensegrity-Inspired Compliant Robotic Upper-Extremity Exosuit. PhD thesis, University of California.

Li H, Yao J, Zhou P, Chen X, Xu Y and Zhao Y (2020) High-force soft pneumatic actuators based on novel casting method for robotic applications. Sensors and Actuators A: Physical 306, 111957.

Li N, Yang T, Yu P, Zhao L, Chang J, Xi N and Liu L (2018) Force point transfer method to solve the structure of soft exoskeleton robot deformation due to the driving force. In 2018 IEEE International Conference on Real-time Computing and Robotics (RCAR). IEEE, pp. 236-241.

Li S, Vogt DM, Rus D and Wood RJ (2017) Fluid-driven origami-inspired artificial muscles. Proceedings of the National Academy of Sciences 114(50), 13132-13137.

Low F, Tan H, Lim JH and Yeow C (2016) Development of a soft pneumatic sock for robot-assisted ankle exercise. Journal of Medical Devices 10(1): 014503.

Low F, Yeow R, Yap H and Lim J (2015) Study on the use of soft ankle-foot exoskeleton for alternative mechanical prophylaxis of deep vien thrombosis. In IEEE International Conference on Rehabilitation Robotics (ICORR). IEEE.

Maciejasz P, Eschweiler J, Gerlach-hahn K, Jansen-troy A and Leonhardt S (2014) A survey on robotic devices for upper limb rehabilitation. Journal of NeuroEngineering and Rehabilitation, Vol 11, Article number: 3 1-29.

Maeder-York P, Clites T, Boggs E, Neff R, Polygerinos P, Holland D, Stirling L, Galloway K, Wee C and Walsh C (2014) Biologically inspired soft robot for thumb rehabilitation. Journal of Medical Devices 8(2): 020933.

Majidi C (2013) Soft robotics: A perspective, current trends and prospects for the future. Soft Robotics 1(1), 5-11.

Malcolm P, Derave W, Galle S and De Clercq D (2013) A simple exoskeleton that assists plantarflexion can reduce the metabolic cost of human walking. PloS one 8(2):e56137.

Manfredi L and Cuschieri A (2019) A Wireless Compact Control Unit (WiCCU) for Untethered Pneumatic Soft Robots. In IEEE International Conference on Soft Robotics (RoboSoft).

Meeker C, Park S, Bishop L, Stein J and Ciocarlie M (2017) Emg pattern classification to control a hand orthosis for functional grasp assistance after stroke. In IEEE International Conference on Rehabilitation Robotics, pp. 1203-1210.

Mengüç Y, Park Y, Pei H, Vogt D, Aubin PM, Winchell E, Fluke L, Stirling L, Wood RJ and Walsh CJ (2014) Wearable soft sensing suit for human gait measurement. International Journal of Robotics Research, Volume: 33 issue: 14, page(s): $1748-1764$.

Miller-Jackson T, Natividad RF and Yeow C (2019a) Simplifying soft robots through adhesive-backed fabrics. In 20192 nd IEEE International Conference on Soft Robotics (RoboSoft). IEEE, pp. 834-839.

Miller-Jackson T, Natividad RF and Yeow C (2019b) Simplifying Soft Robots Through Adhesive-backed Fabrics * Type Type C. In IEEE International Conference on Soft Robotics, (RoboSoft).

Miller-Jackson TM, Li J, Natividad RF and Yeow RC (2019c) STAS: An Antagonistic Soft Pneumatic Actuator Assembly for High Torque Output*. In IEEE International Conference on Soft Robotics, (RoboSoft).

Morales R, Badesa FJ, García-Aracil N, Sabater JM and Pérez-Vidal C (2011) Pneumatic robotic systems for upper limb rehabilitation. Medical and Biological Engineering and Computing 49(10), 1145-1156.

Mosadegh B, Polygerinos P, Keplinger C, Wennstedt S, Shepherd RF, Gupta U, Shim J, Bertoldi K, Walsh CJ and Whitesides GM (2014) Pneumatic networks for soft robotics that actuate rapidly. Advanced functional materials 24(15), 2163-2170.

Murphy P, Adolf G, Daly S, Bolton M, Maurice O, Bonia T, Mavroidis C and Yen S (2014) Test of a customized compliant ankle rehabilitation device in unpowered mode. In International Conference of the IEEE Engineering in Medicine and Biology Society, EMBC 2014.

Natividad R and Yeow C (2016) Development of a soft robotic shoulder assistive device for shoulder abduction. In 2016 6th IEEE International Conference on Biomedical Robotics and Biomechatronics (BioRob). IEEE, pp. 989-993.

Niiyama R, Sun X, Sung C, An B, Rus D and Kim S (2015) Pouch motors: Printable soft actuators integrated with computational design. Soft Robotics 2(2), 59-70.

Nilsson M, Ingvast J, Wikander J and von Holst $\mathbf{H}$ (2012) The soft extra muscle system for improving the grasping capability in neurological rehabilitation. In 2012 IEEE-EMBS Conference on Biomedical Engineering and Sciences. IEEE, pp. $412-417$.

Noritsugu T (2005) Pneumatic soft actuator for human assist technology. In International Symposium on Fluid Power, pp. 11-20.

Noritsugu T, Takaiwa M and Sasaki D (2008) Power assist wear driven with pneumatic rubber artificial muscles. In 15th International Conference on Mechatronics and Machine Vision in Practice, M2VIP'08, pp. 539-544. 
Noritsugu T, Yamamoto H, Sasakil D and Takaiwa M (2004) Wearable power assist device for hand grasping using pneumatic artificial rubber muscle. In SICE 2004 annual conference, Vol. 1. IEEE, pp. 420-425.

Nycz CJ, Delph MA and Fischer GS (2015) Modeling and design of a tendon actuated soft robotic exoskeleton for hemiparetic upper limb rehabilitation. In 2015 37th Annual International Conference of the IEEE Engineering in Medicine and Biology Society (EMBC). IEEE, pp. 3889-3892.

Oguntosin V, Harwin WS, Kawamura S, Nasuto SJ and Hayashi Y (2015) Development of a wearable assistive soft robotic device for elbow rehabilitation. IEEE International Conference on Rehabilitation Robotics (ICORR) 2015, 747-752.

Ohno A, Nabae H and Suzumori K (2015) Static analysis of powered low-back orthosis driven by thin pneumatic artificial muscles considering body surface deformation. In 2015 IEEE/SICE International Symposium on System Integration (SII). IEEE, pp. 39-44.

O’Neill CT, Phipps NS, Cappello L, Paganoni S and Walsh CJ (2017) A soft wearable robot for the shoulder: Design, characterization, and preliminary testing. IEEE International Conference on Rehabilitation Robotics 02129, $1672-1678$.

Panizzolo FA, Freisinger GM, Karavas N, Eckert-Erdheim AM, Siviy C, Long A, Zifchock RA, LaFiandra ME and Walsh CJ (2019) Metabolic cost adaptations during training with a soft exosuit assisting the hip joint. Scientific Reports 9(1), 1-10.

Park H, Lan J, Zhang J, Chen K and Fu C (2019a) Design of a soft wearable device for hip and knee extension assistance. In 2019 5th International Conference on Control, Automation and Robotics (ICCAR). IEEE, pp. 798-801.

Park S and Park C (2019) Suit-type wearable robot powered by shape-memory-alloy-based fabric muscle. Scientific Reports 9(1), 9157.

Park S, Weber LM, Bishop L, Stein J and Ciocarlie M(2018) Design and development of effective transmission mechanisms on a tendon driven hand orthosis for stroke patients. 2018 In IEEE International Conference on Robotics and Automation (ICRA), pp. 2281-2287.

Park S, Yi J, Kim D, Lee Y, Koo HS and Park YL (2019b) A lightweight, soft wearable sleeve for rehabilitation of forearm pronation and supination. In IEEE International Conference on Soft Robotics (RoboSoft).

Park Y, Chen BR, Pérez-Arancibia NO, Young D, Stirling L, Wood RJ, Goldfield EC and Nagpal R (2014a) Design and control of a bio-inspired soft wearable robotic device for ankle-foot rehabilitation. Bioinspiration and Biomimetics 9(1):016007.

Park Y, Chen BR, Young D, Stirling L, Wood RJ, Goldfield E and Nagpal R (2011) Bio-inspired active soft orthotic device for ankle foot pathologies. In IEEE International Conference on Intelligent Robots and Systems, pp. 4488-4495.

Park Y, Santos J, Galloway KG, Goldfield EC and Wood RJ (2014b) A soft wearable robotic device for active knee motions using flat pneumatic artificial muscles. In Proceedings of IEEE International Conference on Robotics and Automation, pp. 48054810.

Perez-Ibarra JC, Alarcon A, Jaimes J, Ortega F, Terra MH and Siqueira AA (2017) Design and analysis of H-force control of a series elastic actuator for impedance control of an ankle rehabilitation robotic platform. In Proceedings of the American Control Conference.

Petersen KH and Shepherd RF (2018) Fluid-driven Intrinsically Soft Robots. In Woodhead Publishing in Materials, Robotic Systems and Autonomous Platforms, Woodhead Publishing, 2019, pp. 61-84, ISBN 9780081022603 Elsevier Ltd.

Poliero T, Natali C, Sposito M, Ortiz J, Graf E, Pauli C, Bottenberg E, De Eyto A and Caldwell DG (2018) Soft wearable device for lower limb assistance: assessment of an optimized energy efficient actuation prototype. In IEEE International Conference on Soft Robotics, (RoboSoft), pp. 559-564.

Polygerinos P, Correll N, Morin SA, Mosadegh B, Onal CD, Petersen K, Cianchetti M, Tolley MT and Shepherd RF (2017) Soft robotics: Review of fluid-driven intrinsically soft devices; manufacturing, sensing, control, and applications in human-robot interaction. Advanced Engineering Materials 19(12):1700016.

Polygerinos P, Wang Z, Overvelde JT, Galloway KC, Wood RJ, Bertoldi K and Walsh CJ (2015) Modeling of Soft FiberReinforced Bending Actuators. IEEE Transactions on Robotics 31(3), 778-789.

Porciuncula F, Roto AV, Kumar D, Davis I, Roy S, Walsh CJ and Awad LN (2018) Wearable movement sensors for rehabilitation: a focused review of technological and clinical advances. Innovations Influencing Physical Medicine and Rehabilitation Wearable, 10(9 Suppl 2):S220-S232.

Quinlivan B, Asbeck A, Wagner D, Ranzani T, Russo S and Walsh CJ (2015) Force transfer characterization of a soft exosuit for gait assistance. In ASME International Design Engineering Technical Conferences \& Computers and Information in Engineering Conference (IDETC/CIE), p. V05AT08A049.

Realmuto J and Sanger T (2019) A robotic forearm orthosis using soft fabric-based helical actuators. In IEEE International Conference on Soft Robotics (RoboSoft).

Ren Y, Wu Y, Yang C, Xu T, Harvey RL and Zhang L (2017) Developing a wearable ankle rehabilitation robotic device for in-bed acute stroke rehabilitation. IEEE Transactions on Neural Systems and Rehabilitation Engineering, 25(6):589-596.

Roam (2009) Roam robotics. Available at https://www.roamrobotics.com/ [accessed 18 April 2019].

Robertson M and Paik J (2017) New soft robots really suck: Vacuum-powered systems empower diverse capabilities. Science Robotics 2(9), eaan6357.

Robertson MA and Paik J (2016) Trunk postural tracking of assistive soft pneumatic actuator belt. In Dynamic Walking Conference.

Sasaki D, Noritsugu T and Takaiwa M (2005a) Development of Active Support Splint driven by Pneumatic Soft Actuator (ASSIST). In IEEE International Conference on Robotics and Automation. 
Sasaki D, Noritsugu T, Takaiwa $\mathbf{M}$ and Yamamoto $\mathbf{H}$ (2005b) Wearable power assist device for hand grasping using pneumatic artificial rubber muscle. In SICE Annual Conference in Sapporo, pp. 655-660.

Schiele A (2009) Ergonomics of exoskeletons: Objective performance metrics. In EuroHaptics conference and Symposium on Haptic Interfaces for Virtual Environment and Teleoperator Systems. IEEE, pp. 103-108.

Schiele A and van der Helm FC (2009) Influence of attachment pressure and kinematic configuration on phri with wearable robots. Applied Bionics and Biomechanics 6(2), 157-173.

Schmidt K, Duarte, JE and Grimmer M, Sancho-Puchades A, Wei H, Easthope C and Riener R (2017) The myosuit: Bi-articular anti-gravity exosuit that reduces hip extensor activity in sitting transfers. Frontiers in Neurorobotics 11, pp.57.

Schmitt F, Piccin O, Barbé L and Bayle B (2018) Soft robots manufacturing: A review. Frontiers in Robotics and AI 5 pp. 84.

Sedal A, Fisher M, Bishop-Moser J, Wineman A and Kota S (2018) Auxetic sleeves for soft actuators with kinematically varied surfaces. In IEEE/RSJ International Conference on Intelligent Robots and Systems (IROS), pp. 464-471.

Shiota K, Kokubu S, Tarvainen TV, Sekine M, Kita K, Huang S and Yu W (2019) Enhanced Kapandji test evaluation of a soft robotic thumb rehabilitation device by developing a fiber-reinforced elastomer-actuator based 5-digit assist system. Robotics and Autonomous Systems 111, 20-30.

Siviy C, Galiana I, Holt KG, Walsh CJ, Panizzolo FA, Malcolm P, Crea S, Lee S and Saucedo F (2017) Varying negative work assistance at the ankle with a soft exosuit during loaded walking. Journal of NeuroEngineering and Rehabilitation, 14, Article number: 62.

Sovero S, Talele N, Smith C, Cox N, Swift T and Byl K (2016) Initial data and theory for a high specific-power ankle exoskeleton device. In International Symposium on Experimental Robotics. Springer, pp. 355-364.

Spector WD and Fleishman JA (1998) Combining activities of daily living with instrumental activities of daily living to measure functional disability. The Journals of Gerontology Series B: Psychological Sciences and Social Sciences 53(1), S46-S57.

Teng C, Wong Z, Teh W and Chong YZ (2012) Design and development of inexpensive pneumatically-powered assisted kneeankle-foot orthosis for gait rehabilitation-preliminary finding. In 2012 International Conference on Biomedical Engineering, ICOBE 2012.

Thakur C, Ogawa K, Tsuji T and Kurita Y (2018) Soft wearable augmented walking suit with pneumatic gel muscles and stance phase detection system to assist gait. IEEE Robotics and Automation Letters 2018 IEEE/RSJ International Conference on Intelligent Robots and Systems (IROS) 3(4), 4257-4264.

Thalman CM, Hertzell T and Lee H (2020) Toward a soft robotic ankle-foot orthosis (sr-afo) exosuit for human locomotion: Preliminary results in late stance plantarflexion assistance. In IEEE International Conference on Soft Robotics, (RoboSoft). IEEE.

Thalman CM, Hsu J, Snyder L and Polygerinos P (2019) Design of a soft ankle-foot orthosis exosuit for foot drop assistance. In 2019 International Conference on Robotics and Automation (ICRA). IEEE, pp. 8436-8442.

Thalman CM, Lam Q, Nguyen PH, Sridar S and Polygerinos P (2018) A novel soft elbow exosuit to supplement bicep lifting capacity. In 2018 IEEE/RSJ International Conference on Intelligent Robots and Systems (IROS), pp. 6965-6971.

Thalman CM and Lee H (2020) Design and validation of a soft robotic ankle-foot orthosis (srafo) exosuit for inversion and eversion ankle support. In 2019 International Conference on Robotics and Automation (ICRA). IEEE.

Tripanpitak K, Tarvainen TV, Sonmezisik I, Wu J and Yu W (2018) Design a soft assistive device for elbow movement training in peripheral nerve injuries. 2017 IEEE International Conference on Robotics and Biomimetics, ROBIO $20172018,544-548$.

Wang X (2016) Identification for a Class of Soft Pneumatic Actuators. PhD thesis, University of Surrey (United Kingdom).

Wearable Robotics Association (2015) Wearable robots. Available at http:/www.wearablerobotics.com/wearable-robots/ [accessed April 2020].

Wehner M, Park Y, Walsh C, Nagpal R, Wood R, Moore T and Goldfield E (2012) Experimental characterization of components for active soft orthotics. In 2012 th IEEE RAS \& EMBS International Conference on Biomedical Robotics and Biomechatronics (BioRob). IEEE, pp. 1586-1592.

Wehner M, Quinlivan B, Aubin PM, Martinez-Villalpando E, Baumann M, Stirling L, Holt K, Wood R and Walsh C (2013) A lightweight soft exosuit for gait assistance. In 2013 IEEE International Conference on Robotics and Automation (ICRA), 610 May 2013, p. 5863.

Wilkening A, Stoppler H and Ivlev O (2015) Adaptive assistive control of a soft elbow trainer with self-Alignment using pneumatic bending joint. IEEE International Conference on Rehabilitation Robotics 2015, 729-734.

Wirekoh J and Park Y-L. (2017) Design of flat pneumatic artificial muscles. Smart Materials and Structures 26(3), 035009.

Wu Q, Wang X, Du F and Zhang X (2015) Design and control of a powered hip exoskeleton for walking assistance. International Journal of Advanced Robotic Systems, Volume: 12 issue: 3.

Xiloyannis Mand Cappello L, Binh KD, Antuvan CW and Masia L (2017) Preliminary design and control of a soft exosuit for assisting elbow movements and hand grasping in activities of daily living. Journal of Rehabilitation and Assistive Technologies Engineering, 4: 1-15.

Yandell MB, Quinlivan BT, Popov D, Walsh CJ and Zelik KE (2017) Physical interface dynamics alter how robotic exosuits augment human movement: implications for optimizing wearable assistive devices. Journal of NeuroEngineering and Rehabilitation 14(1), 40 .

Yandell MB, Tacca JR and Zelik KE (2019) Design of a low profile, unpowered ankle exoskeleton that fits under clothes: Overcoming practical barriers to widespread societal adoption. IEEE Transactions on Neural Systems and Rehabilitation Engineering, 27(4):712-723. 
Yandell MB, Ziemnicki DM, McDonald KA and Zelik KE (2020) Characterizing the comfort limits of forces applied to the shoulders, thigh and shank to inform exosuit design. Plos One 15(2), e0228536.

Yang HD (2017) Modeling and Analysis of a Novel Pneumatic Artificial Muscle and Pneumatic Arm Exoskeleton. PhD thesis, Virginia Tech.

Yang HD and Asbeck AT (2018) A new manufacturing process for soft robots and soft/rigid hybrid robots. In 2018 IEEE/RSJ International Conference on Intelligent Robots and Systems (IROS). IEEE, pp. 8039-8046.

Yang X, Huang T, Hu H, Yu S, Zhang S, Zhou X, Carriero A, Yue G and Su H (2019) Spine-inspired continuum soft exoskeleton for stoop lifting assistance. IEEE Robotics and Automation Letters 4(4), 4547-4554.

Yap H, Goh J and Yeow R (2015a) Rehabilitation applications. In 6th European conference of the International Federation for Medical and Biological Engineering. Springer, pp. 367-370.

Yap H, Ng HY and Yeow C (2016) High-force soft printable pneumatics for soft robotic applications. Soft Robotics 3(3), 144-158.

Yap HK, Khin PM, Koh T, Sun Y, Liang X, Lim JH and Yeow C (2017) A fully fabric-based bidirectional soft robotic glove for assistance and rehabilitation of hand impaired patients. IEEE Robotics and Automation Letters 2(3), 1383-1390.

Yap HK, Lim JH, Nasrallah F, Goh JC and Yeow RC (2015b) A soft exoskeleton for hand assistive and rehabilitation application using pneumatic actuators with variable stiffness. In 2015 IEEE international conference on robotics and automation (ICRA). IEEE, pp. 4967-4972.

Yariott JM (1972) Fluid actuator. US Patent 3,645,173.

Zhang X, Shtarbanov A, Zeng J, Chen VK, Bove M, Maes P and Rekimoto J (2019a) Bubble: Wearable assistive grasping augmentation based on soft inflatables. In Extended Abstracts of the 2019 CHI Conference on Human Factors in Computing Systems, pp. 1-6.

Zhang Y, Kleinmann RJ, Nolan KJ and Zanotto D (2019b) Preliminary validation of a cable-driven powered ankle-foot orthosis with dual actuation mode. IEEE Transactions on Medical Robotics and Bionics 1(1), 30-37.

Zhao H, Jalving J, Huang R, Knepper R, Ruina A and Shepherd R (2016) A helping hand: Soft orthosis with integrated optical strain sensors and emg control. IEEE Robotics and Automation Magazine 23(3), 55-64.

Zhu M, Adams W and Polygerinos P (2017) Carpal Tunnel syndrome soft relief device for typing applications. In ASME Design of Medical Devices Conference (DMD 2017).

Cite this article: Thalman C and Artemiadis P (2020). A review of soft wearable robots that provide active assistance: Trends, common actuation methods, fabrication, and applications. Wearable Technologies, 1, e3, doi:10.1017/wtc.2020.4 